Louisiana State University

LSU Digital Commons

2013

\title{
Effects of a Brief Mindfulness Intervention on Negative Affect and Urge to Drink Among College Student Drinkers
}

Christine Vinci

Louisiana State University and Agricultural and Mechanical College

Follow this and additional works at: https://digitalcommons.Isu.edu/gradschool_dissertations

Part of the Psychology Commons

\section{Recommended Citation}

Vinci, Christine, "Effects of a Brief Mindfulness Intervention on Negative Affect and Urge to Drink Among College Student Drinkers" (2013). LSU Doctoral Dissertations. 956.

https://digitalcommons.Isu.edu/gradschool_dissertations/956

This Dissertation is brought to you for free and open access by the Graduate School at LSU Digital Commons. It has been accepted for inclusion in LSU Doctoral Dissertations by an authorized graduate school editor of LSU Digital Commons. For more information, please contactgradetd@lsu.edu. 


\title{
EFFECTS OF A BRIEF MINDFULNESS INTERVENTION ON NEGATIVE AFFECT AND URGE TO DRINK AMONG COLLEGE STUDENT DRINKERS
}

\author{
A Dissertation \\ Submitted to the Graduate Faculty of the \\ Louisiana State University and \\ Agricultural and Mechanical College \\ in partial fulfillment of the \\ requirements for the degree of \\ Doctor of Philosophy
}

in

The Department of Psychology

\author{
by \\ Christine Vinci \\ B.S., Louisiana State University, 2007 \\ M.S., University of South Carolina Aiken, 2009
}

August 2014 


\section{ACKNOWLEDGEMENTS}

I would like to thank all those individuals who have influenced my ability to succeed in graduate school. These include my mentors not only from Louisiana State University (LSU), but also those from the University of South Carolina Aiken (USCA) where I received my master's degree. In particular, I would like to thank Dr. Amy Copeland, who was my graduate school advisor at LSU, and Dr. Maureen Carrigan, who was my thesis mentor at USCA. Both of these women have greatly impacted my professional development and have provided unending support over the years.

I would also like to thank other mentors who have contributed to my educational training - Dr. Edward Callen, Dr. Jane Stafford, Dr. Claire Advokat, Dr. Glenn Jones, Dr. Tom Davis, and Dr. Scott Coffey. These individuals provided guidance at various parts of the graduate school process and are each responsible for my academic and professional development in some way.

Finally, I would like to thank my family and friends, including my lab members and internship cohort, for their consistent support throughout the years. Words cannot capture the continuous guidance and support they have provided in so many ways; without them, this journey may have not been possible. 


\section{TABLE OF CONTENTS}

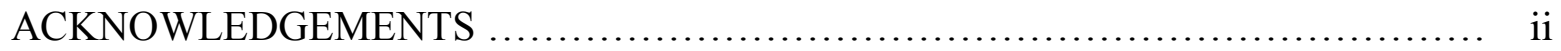

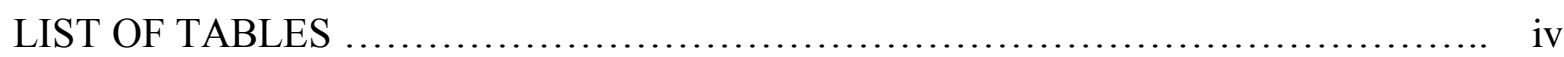

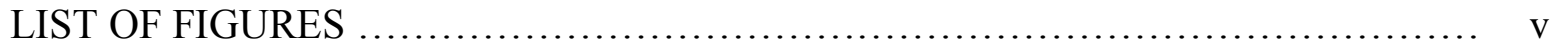

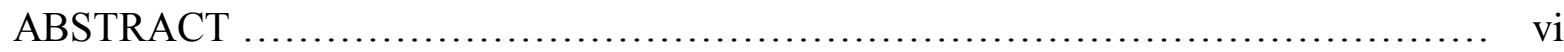

CHAPTER

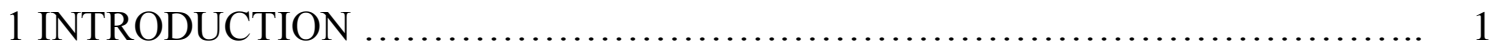

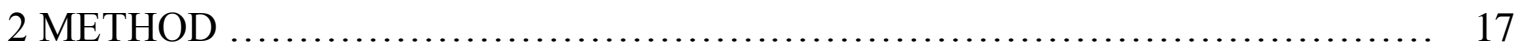

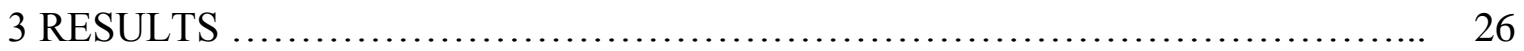

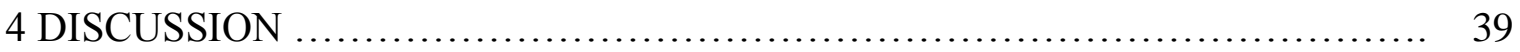

REFERENCES ................................................................. 44

APPENDIX

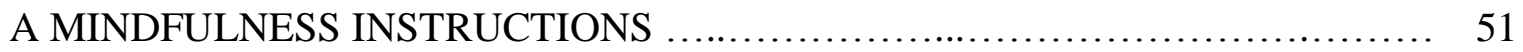

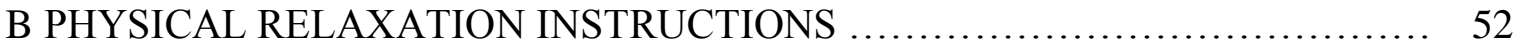

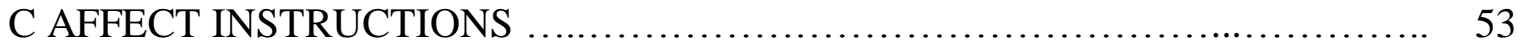

D COPYRIGHT INFORMATION ......................................... 54

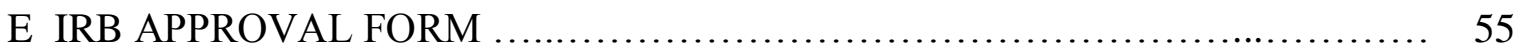

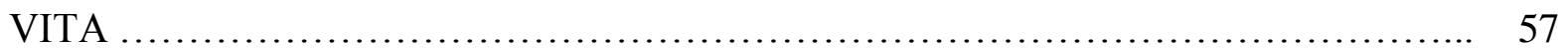




\section{LIST OF TABLES}

1. Participants Distribution in Groups ........................................ 27

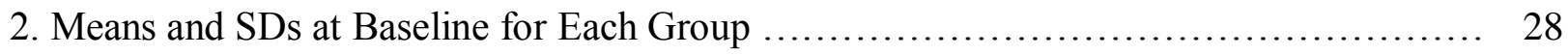

3. Manipulation Check Means and Standard Deviations for Changes in Mindfulness

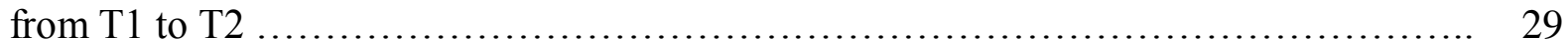

4. Manipulation Check Means and Standard Deviations for Changes in Relaxation

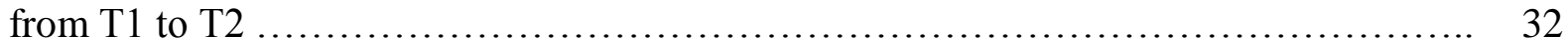

5. Manipulation Check Means and Standard Deviations for Changes in NA

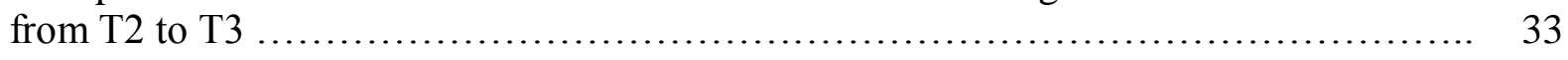

6. NA and Urge Estimated Marginal Means and Standard Errors for Each Group Across Time

7. Willingness to Watch Images and Time to Next Drink Means and Standard Deviations for each Group at T3 


\section{LIST OF FIGURES}

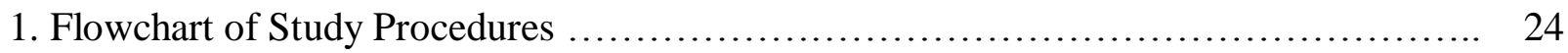

2. TMS Curiosity Ratings Pre- and Post-Interventions (T1 vs T2) ................. 30

3. TMS Decentering Ratings Pre- and Post-Interventions (T1 vs T2) ................ 31

4. Relaxation/Tension Ratings Pre- and Post-Interventions (T1 vs T2) ............... 33

5. NA Ratings Pre- and Post-Affect Induction (T2 vs T3) $\ldots \ldots \ldots \ldots \ldots \ldots \ldots \ldots \ldots \ldots \ldots \ldots$

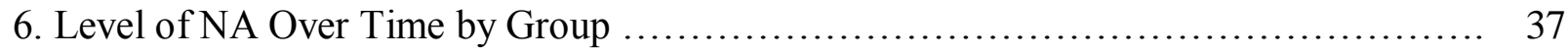

7. Level of Urge Over Time by Group ....................................... 37 


\begin{abstract}
Problematic college student drinking can predict the subsequent development of severe alcohol use patterns. Several theories have proposed that negative affect (NA) plays a large role in the maintenance of substance use behaviors - a phenomenon supported in laboratory-based and clinical studies. It has been demonstrated that mindfulness meditation can improve the regulation of NA, suggesting that mindfulness may be very beneficial in treating problematic substance use behavior. The present study utilized a brief mindfulness intervention, followed by a NA mood induction in a sample of college student problematic drinkers $(N=207)$. A three by two by three factorial design was used to cross Group (Mindfulness, Relaxation, Control), Affect (negative, neutral), and Time (Time 1 [T1], Time 2 [T2], Time 3 [T3]). Participants were randomly assigned to the Group and Affect conditions and assessed across Time for level of NA and urge to drink alcohol via four outcome variables. It was hypothesized that those in the Mindfulness + NA condition would report lower levels of NA, increased willingness to experience NA, lower urges to drink, and less time to next alcoholic drink following the mindfulness intervention and NA induction, as compared to those participants in the Relaxation and Control groups. A $3 \times 2 \times 3$ repeated measures multivariate analysis of variance (MANOVA) was used to determine whether the groups differed on level of NA and urge to drink over the three time periods (T1, T2, T3). A one-way ANOVA was conducted to evaluate whether groups differed on willingness to continue experiencing NA and time to next drink, which were measured at the end of the experiment. Results indicated that the mindfulness intervention was effective at increasing level of state mindfulness and decreasing level of NA, above and beyond that of the control group. However, these changes did not maintain following the affect induction and thus the primary hypotheses were not supported. One potential reason for this may be that the mindfulness intervention was
\end{abstract}


not strong enough (e.g., too brief). Recommendations for future research based on these findings are discussed. 


\section{INTRODUCTION}

In the United States, $51.8 \%$ of individuals 12 and older reported drinking alcohol in 2010 (Substance Abuse and Mental Health Services Administration [SAMHSA], 2011). ${ }^{1}$ Alcohol use is particularly common among college students, as they report higher rates of drinking alcohol, binge drinking (five or more drinks on one occasion), and heavy drinking (five or more drinks on one occasion on five or more days in past month) than non-college students in the past month-a statistic that has been consistent since the early 1990s (SAMSHA, 2011; Wechsler et al., 2002). Specifically, $63.3 \%$ of college students report drinking alcohol, $42.2 \%$ of whom report binge drinking and $15.6 \%$ report heavy drinking (SAMHSA, 2011).

The number of college students endorsing binge drinking in the past 90 days has been estimated to be as high as $84.2 \%$ (Vik, Carrello, Tate, \& Field, 2000). Perkins (2002), in a review of the literature of college student drinking, revealed multiple negative consequences often occurring due to heavy drinking, including academic impairment, unintended and unprotected sexual activity, impaired driving, suicidal ideation and attempts, property damage, and interpersonal violence. College student binge drinking has also been found to predict future occurrence of alcohol-related problems (e.g., employment difficulties, lower educational attainment) and the development of alcohol-related disorders in a 10-year follow-up study (Jennison, 2004).

\footnotetext{
${ }^{1}$ This document previously appeared as: Vinci, C., Peltier, M. R., Shah, S., Kinsaul, J., Waldo, K., McVay, M., \& Copeland, A. L. (2014). Effects of a brief mindfulness intervention on negative affect and urge to drink among college student drinkers. Behaviour Research and Therapy. doi: http://dx.doi.org/10/1016/j.brat.2014.05.012,1. It is reprinted by permission of Elsevier.
} 


\section{Substance Use and Negative Affect}

Watson, Clark, and Tellegen (1988) define negative affect (NA) as "a general dimension of subjective distress and unpleasureable engagement that subsumes a variety of aversive mood states, including anger, contempt, disgust, guilt, fear, and nervousness, with low NA being a state of calmness and serenity" (p. 1063). Baker and colleagues (Baker, Piper, McCarthy, Majiskie, \& Fiore, 2004) posit that NA is implicated in the withdrawal process from a substance. The Affective Model of Drug Motivation (Baker et al., 2004) postulates that drug use is maintained because the individual is attempting to avoid or escape NA. Furthermore, while NA can be triggered by a variety of stimuli (e.g., people, situations, events), it can also be triggered once drug levels in the body have decreased (i.e., the beginning of withdrawal). This may then prompt the individual to use the substance in order to alleviate feelings of NA due to withdrawal. Baker and colleagues (2004) suggest that the user first recognizes interoceptive cues of NA when the drug is not immediately available. These cues and the unavailability of the substance become connected, and the individual discovers that using the drug will alleviate NA. In other words, NA becomes a conditioned stimulus (CS) for the individual, with any type of interpersonal stressor triggering the individual to experience the conditioned response (CR) of craving $^{2}$.

Researchers have shown a relationship between acute emotional states and urges to use substances. Laboratory research has shown that urge to smoke cigarettes and/or cigarette smoking behaviors increase when NA is induced (Conklin \& Perkins, 2005; Parrott \& Garnham,

\footnotetext{
${ }^{2}$ The definition of craving has been explained in various ways; a common definition in the literature is "a subset of desires or urges that have crossed a subjective threshold of intensity" (Kozlowski \& Wilkinson, 1987, p. 33). Similarly, urge has been defined in different ways, a typical definition being "a feeling of being impelled to do something" (West, 2006, p. 88). While the differences between the two have been noted here, much of the substance literature uses the two words interchangeably. Thus, the terms urge and craving will be used synonymously throughout this paper.
} 
1998; Vinci, Copeland, \& Carrigan, 2012; Willner \& Jones, 1996) and that the urge to drink increases when individuals experience NA (Cooney, Litt, Morse, Bauer, \& Guapp, 1997). Alcohol use has been found to decrease NA in laboratory settings (Kusher, McKenzie, Fiszdon, Valentiner, \& Foa, 1996) and in real-time, as monitored by ecological momentary assessment (EMA; Armeli et al., 2003).

Increases in NA have been associated with relapse as well, with most research supporting this relationship in either cigarette smokers or alcohol users. When monitoring smoking behaviors with EMA, relapse rates increased when higher levels of NA were reported (Shiffman et al., 2007). In a sample of treatment-seeking alcohol users, higher NA was related to heavier and more frequent drinking post-treatment (Witkiewitz \& Villarroel, 2011). Finally, following treatment for alcohol and cigarette use, those who experienced elevated depression were more likely to relapse post-treatment than those without elevated depression scores (Kodl et al., 2008). These findings indicate that NA is greatly implicated not only in the use of substances, but also in risk of relapse.

One potential intervention strategy to help reduce the likelihood of relapse in response to NA involves teaching individuals to cope with NA instead of trying to avoid or escape it. The practice of mindfulness, as a technique to manage unpleasant experiences (e.g., thoughts, affect), has recently been applied to substance use treatments. Specifically, Mindfulness-Based Relapse Prevention (MBRP) has gained empirical support for reducing substance use post-treatment (Bowen et al., 2009; Brewer et al., 2009; Witkiewitz \& Bowen, 2010).

\section{Mindfulness}

Mindfulness practice is historically rooted in Eastern tradition, specifically within Buddhism (Marlatt, 2002). However, over the past 20 or so years, mindfulness has been 
examined as a potential intervention for various psychological disorders (Shapiro, Carlson, Astin, \& Freedman, 2006). Jon Kabat-Zinn (1994) defined mindfulness as "paying attention in a particular way: on purpose, in the present moment, and nonjudgmentally" (p. 4). Three main components of mindfulness, which occur simultaneously, have been specified to include: attention (paying attention), intention (purposefully), and attitude (in a particular way, with acceptance and non-judgment; Shapiro et al., 2006). When assessing an individual's level of mindfulness, there are several components to consider, as mindfulness is generally not viewed as a single construct. Following a factor analysis of several mindfulness questionnaires, Baer and colleagues (Baer, Smith, Hopkins, Krietemeyer, \& Toney, 2006) posited five different facets of mindfulness: (1) “Observing/noticing/attending to sensations/perceptions/thoughts/feelings," (2) “Describing/labeling with words," (3) "Nonreactivity to inner experience," (4) “Acting with awareness/automatic pilot/concentration/nondistraction," and (5) "Nonjudging of experience" (pp. 34-35). Overall, mindfulness can be described as paying attention to the present moment (including thoughts, emotions, physical sensations), with an attitude of nonjudgment and acceptance.

Mindfulness has been conceptualized as both a cognitive and behavioral strategy. Specifically, it has been viewed as a way to allow controlled, thoughtful processing, which helps the individual observe emotions and thoughts, rather than reacting to them (Breslin, Zack, \& McMain, 2002). One technique used to reach that goal is "reperceiving," a method used to shift the way an individual views his/her current situation, such that a given experience is viewed from an outside, objective perspective. This allows the individual to distance himself or herself from a certain experience and decrease judgment (of the experience, his/her reaction, or both) while increasing acceptance of the given situation. Therefore, the individual gains a potentially 
better perspective on the situation, before deciding his/her next course of action (Shapiro et al., 2006), than if he/she were to simply react to the situation without being thoughtful. This concept is similar to "cognitive diffusion" where an individual attempts to change his/her relationship with a thought rather than the thought content itself (as attempting to change the thought content implies a negative judgment value on the thought; Hayes, Strosahl, \& Wilson, 1999). Thus, these mindful cognitive techniques vary from traditional cognitive strategies, in which one identifies problematic thoughts with the intention of changing them, therefore placing a negative value on the thought (Witkiewitz, Marlatt, \& Walker, 2005).

Behavioral aspects of mindfulness have been conceptualized as a form of exposure in which one attends to a situation mindfully. Specifically, the individual attends to thoughts, emotions, and physical sensations in the present moment, without judging them or engaging in avoidance behaviors. Essentially, mindfulness can be viewed as a type of extinction in which learning to be mindful is the CR (Breslin et al., 2002; Shapiro et al., 2006). For instance, instead of using a substance when feeling an unpleasant emotion, the CR becomes being mindful of the present experience and, therefore, allows the individual to decide how to manage the craving. Mindfulness also targets avoidance behaviors (i.e., engagement in negative reinforcement to alleviate unpleasant experiences), as mindfulness teaches nonavoidance of unpleasant experiences. Using a substance to feel better is a form of negative reinforcement; thus, mindfulness practices may directly target such behaviors in substance users (Breslin et al., 2002; Shapiro et al., 2006).

Mindfulness-based interventions also consist of a relaxation component, as they typically allow participants to become more physically relaxed (Baer, 2003; Shapiro, 1982). Research comparing mindfulness and relaxation interventions have found that both decrease levels of 
distress and increase positive mood (Jain et al., 2007). However, mindfulness interventions may have additional benefits such as decreasing ruminative thoughts (Jain et al., 2007) and increasing aspects of mindfulness (e.g., decentering; Feldman, Greeson, \& Senville, 2010).

Mindfulness has been incorporated into several different cognitive behavioral therapies (CBTs) for psychological problems including Acceptance and Commitment Therapy (ACT; Hayes et al., 1999), Mindfulness-Based Cognitive Therapy for depression (MBCT; Segal, Williams, \& Teasdale, 2002), Mindfulness-Based Stress Reduction for chronic pain (MBSR; Grossman, Niemann, Schmidt, \& Walach, 2004; Kabat-Zinn, 1982, 1990; Kabat-Zinn, Lipworth, \& Burney, 1985), Dialectical Behavioral Therapy (DBT) for Borderline Personality Disorder (BPD; Linehan, 1993), and MBRP for substance use disorders (Bowen, Chawla, \& Marlatt, 2011; Witkiewitz et al., 2005).

\section{Mindfulness: Relationship to Psychological Health and Physiological Response}

Various mindfulness interventions have been developed for different mental health issues, with some of the following problems showing improvements following mindful interventions: mood disturbance and stress (Speca, Carlson, Goodey, \& Angen, 2000), relapse to depression (Teasdale et al., 2000), suicidal behaviors (Linehan, Armstrong, Suarez, \& Russell, 1991), and sleep problems (Shapiro, Bootzin, Figeuredo, Lopez, \& Schwartz, 2003). Brown and Ryan (2003) examined mindfulness in relation to psychological well-being and found that mindfulness is significantly associated with several aspects of well-being including optimism, life satisfaction, self-esteem, and positive affectivity, while negatively correlated with depression, anxiety, NA, and neuroticism. Mindfulness has also been found to be associated with lower levels of anxiety (McKee, Zvolensky, Solomon, Bernstein, \& Lenn-Feldner, 2007). 
Mindfulness has been studied as a type of executive function, as it targets attention, emotion regulation, inhibition of behaviors, and ultimately facilitates decision making (Black, Semple, Pokhrel, \& Grenard, 2011). Tang and colleagues (Tang et al., 2007) examined a mindfulness intervention on executive attention and mood, as well as cortisol and immunoreactivity levels following a cognitive challenge task. Forty participants were randomly assigned to a mindfulness meditation group, which consisted of being led through meditation by trained coaches in groups over five days, for 20 minutes per day. Forty participants were also randomly assigned to the control group, which consisted of basic relaxation training. Results indicated that the mindfulness group, when compared to the basic relaxation group, demonstrated significantly more efficient executive attention results, decreases in negative mood, increases in positive mood, and a better physiological stress response following the cognitive challenge.

Based on the above findings, Tang and colleagues (2009) conducted a follow-up study to further examine the impact of mindfulness meditation on the central and autonomic nervous systems. Findings indicated that following the mindfulness intervention, participants had lower heart rate, skin conductance, and chest respiratory rate, and increased belly respiratory amplitude compared to participants in the relaxation intervention. These results suggest that the mindfulness group was more relaxed physiologically than the relaxation group. Furthermore, brain imaging revealed that the mindfulness group had increased regional cerebral blood flow in the right anterior cingulate cortex, as well as areas such as the left insula, putamen, and right posterior cingulate cortex than the relaxation group. These areas of the brain are implicated in reward, decision making, emotion, and empathy. Thus, the authors posit that mindfulness meditation may also create change in brain patterns, allowing the individual to become even more relaxed, than he or she would be without such training. 


\section{Mindfulness and Affect}

Mindfulness may serve three specific functions regarding affect: (1) decreasing NA, (2) increasing positive affect (PA), and (3) changing an individual's response to NA when it does occur. Davidson and colleagues (2003), in a randomized controlled trial of an 8-week program of MBSR, discovered increases in left side anterior activation in the brain, an area associated with PA. Decreases in NA and increases in PA following five days of meditation training have also been found (Tang et al., 2007). Jain and colleagues (Jain et al., 2007) discovered that after four sessions of mindful meditation, participants reported decreases in general distress and increases in positive states of mind.

Mindfulness interventions have also been shown to change response to NA when it occurs. MBCT was developed in order to alter the way an individual responds to NA and cognitions as they relate to depression, specifically aiming to decrease "cognitive reactivity" (Raes, Dewulf, Van Heeringen, \& Williams, 2009). This is done by learning to recognize increases in depressive mood and thoughts, while observing these changes nonjudgmentally. Results indicated that mindfulness was negatively associated with cognitive reactivity, and that by extension, MBCT decreased cognitive reactivity. In addition, increases in mindfulness skills mediated the relationship of MBCT on cognitive reactivity, such that the greater the mindfulness skill increase, the greater the impact MBCT had on cognitive reactivity, thereby rendering participants less cognitively reactive.

Ortner, Kilner, and Zelazo (2007) examined the effect of mindfulness meditation on response to affective stimuli (i.e., negative, neutral, and positive images) in a college student sample. Findings indicated that individuals more experienced in meditation had lower levels of interference on a cognitive task when viewing affective images. Interference was measured by 
participants' reaction times indicating whether a tone they heard was low or high; lower levels of interference (as opposed to high levels) suggest that the participants were better able to manage affect while viewing the images. The second part of the study examined interference on the same task following either 7 weeks of mindfulness meditation or relaxation. Individuals in the mindfulness meditation group demonstrated decreases in interference when presented with affective images. The authors concluded that the ability to disengage from the emotional content allowed participants to perform better on the cognitive task.

Arch and Craske (2006) implemented a 15-minute breathing induction (consistent with mindfulness meditation instructions) in a sample of healthy undergraduates in order to determine if participants in the breathing group differed in response to NA images when compared to those in the worry group (asked to worry about six different topics) or unfocused attention group (asked to think about whatever came to mind). Results showed that those in the breathing group endorsed lower levels of NA after watching NA images when compared to the worry group, and an increased willingness to continue viewing the NA images when compared to the unfocused attention group. The authors postulated that those in the breathing group were potentially less overwhelmed by the NA slides and were able to manage their NA more adaptively, such that they were willing to continue watching the images.

\section{Mindfulness and Substance Use}

More recently, the relationship between mindfulness and substance use has been examined. Specifically, Philip (unpublished thesis, 2010) found that quantity and frequency of drinking in college students is negatively correlated with trait mindfulness; additionally, level of mindfulness was predictive of problematic drinking behavior. In a sample of medical students, those endorsing current meditation practice (i.e., meditation, yoga, tai chi, relaxation techniques) 
were less likely to drink alcohol and have problematic alcohol use (according to their score on the Alcohol Use Disorders Identification Test [AUDIT]) than those who did not report practicing meditation regularly (Black et al., 2011). These studies indicate that a relationship exists between mindfulness and alcohol use. It is important to recognize that while those who are higher in mindfulness and/or meditate indicate drinking less and having fewer drinking problems than those who do not, it might also be the case that those high in mindfulness and who meditate are less likely to be drinkers in the first place.

Using the Five Facet Mindfulness Questionnaire (FFMQ), Fernandez and colleagues (Fernandez, Wood, Stein, \& Rossi, 2010) found that "describing" and "acting with awareness" were negatively associated with alcohol use and that "nonjudging" was negatively associated with problematic alcohol consequences (e.g., blackouts, driving while intoxicated, missing class due to substance use). Finally, Ostafin and Marlatt (2008) found that "acceptance of present experiences" moderated the relationship between implicit associations of alcohol and problematic drinking (endorsement of items such as getting injured while drinking), such that the relationship between implicit associations and problematic drinking was weakened for those more likely to accept current experiences. These studies suggest that mindfulness may be a protective factor regarding both alcohol use and problematic drinking behaviors.

Few studies have examined the direct impact of a mindfulness intervention on substance use outcomes; however, those that have studied this relationship have found consistent results. Bowen and colleagues (2006) examined the impact of Vipassana Meditation (VM) on the use of alcohol, marijuana, and cocaine in an incarcerated population. VM consists of a 10-day course of meditation focusing on examining the self with an objective perspective. VM courses involve up to 11 hours of meditation over the 10 days, which are conducted in silence. VM is thought to 
target urges to use a substance by having the individual learn to observe such experiences without directly acting on them at that moment; instead, he/she learns other ways to manage thoughts related to urge. Results indicated that those participating in the VM were less likely to experience alcohol-related consequences (e.g., impulse control problems, interpersonal consequences, social responsibility) and less likely to use alcohol, marijuana, and cocaine upon prison release than those in the treatment as usual (TAU) group. In another study, Qigong meditation was provided to substance users in a residential facility on a voluntary basis and compared to Stress Management and Relaxation Training (part of TAU for this facility; Chen, Comerford, Shinnick, \& Ziedonis, 2010) over 14-28 days (depending on the length of stay for a given individual). Qigong meditation consisted of relaxation, imagery, attention, and mindfulness to the present moment. Results indicated that those in the meditation group reported significantly fewer cravings and withdrawal symptoms and less anxiety at the 2-week assessment point, as compared to the control condition. A major limitation to both of these studies was that participants self-selected into the VM and Qigong meditation groups, which could impact the findings.

In a pilot study conducted by Davis and colleagues (Davis, Fleming, Bonus, \& Baker, 2007), the impact of a mindfulness intervention on smoking cessation was examined. MBSR was modified to target smoking behaviors over an 8-week treatment period. At the 6-week post-quit assessment date, $56 \%$ of participants were abstinent, confirmed by carbon monoxide readings. Additionally, participants demonstrating increased compliance with the meditation were more likely to maintain abstinence and exhibited greater reductions in NA. Given that participants maintaining abstinence also reported reduction in NA, the authors posit that mindfulness may be 
specifically targeting affect. They note that decreases in NA may then impact smoking behaviors, such that participants are more likely to maintain abstinence.

Brief mindfulness interventions have also been developed and implemented in laboratory-based settings to target substance use behaviors. Bowen and Marlatt (2009) provided college student cigarette smokers interested in reducing their smoking with a brief mindfulness intervention (about 11 minutes) targeted at managing urge to smoke. Participants were assigned to either a mindfulness intervention or to the control group. Both groups underwent a cue exposure trial in which participants were presented with visual cues of smoking for 4-6 minutes. Participants in the mindfulness group were then guided through a meditation asking them to attend to thoughts and urges without trying to get rid of them. According to the study procedures, instructions were consistent with "urge surfing," a specific mindfulness technique tailored to attending to urges as they come and go. The control group was instructed to focus on past coping skills to manage craving.

Results indicated no differences between groups regarding affect or urge on the day of the intervention. However, over the 7-day follow-up, the mindfulness group reported smoking fewer cigarettes per day than the control group, with the effect resulting in a medium to large effect size $(d=.64)$. Additionally, on the $7^{\text {th }}$ day, significant differences between groups on cigarettes smoked per day were still observed. The authors suggest that participants in the mindfulness group changed in their response to urges over the week period, resulting in decreased smoking behavior (Bowen \& Marlatt, 2009). These findings provide support for a very brief mindfulness intervention regarding changes in smoking behavior.

Vernig and Orsillo (2009) examined emotional reaction to an affect induction, following a mindfulness intervention in a sample of alcohol dependent and non-dependent college students. 
Participants in the mindfulness group viewed an eight and a half minute video presenting them with mindfully-based instructions on how to manage unpleasant emotions; the control group watched a video where an article from National Geographic was read. Participants then viewed images from the International Affective Picture System (IAPS) for the mood induction procedure (positive, neutral, and negative images were presented), lasting for five minutes. Results indicated that while alcohol dependent participants were more likely to endorse drinking to cope with NA than the non-dependent participants, no significant differences emerged between those undergoing the mindfulness intervention versus the neutral. The authors suggest that the small sample size $(n=48)$, low severity of alcohol dependence, and lack of information on motives for drinking contributed to non-significant findings. Furthermore, given that prior studies have found that participants' self-reported affect may not change at that moment, response to affect may be affected (e.g., willingness to continue watching unpleasant images; Bowen \& Marlatt, 2009); measures assessing response to affect were not assessed here. This study also used a video tape instructing participants on mindfulness, instead of actually guiding participants through a mindfulness meditation. Finally, participants were also not instructed to apply the skills discussed in the video when watching the affective images. Procedural issues such as these may have also impacted the study's null findings.

While many studies have examined the impact of brief mindfulness interventions on substance use behaviors, MBRP is a treatment incorporating both the strategies of CBT and mindfulness meditation practice, usually delivered in an 8-session group format (Bowen et al., 2011). MBRP is a treatment for individuals who have already undergone standard drug treatment as a way to help prevent relapse by providing additional skills to manage urges and create relapse prevention plans. Multiple studies have demonstrated the efficacy of MBRP on symptoms 
related to substance use (i.e., decreases in craving and use and managing of NA), including two randomized controlled trials (RCT; Bowen et al., 2009; Brewer et al., 2009).

Bowen and colleagues (Bowen et al., 2009) found that MBRP provided to individuals following initial substance use treatment resulted in decreased craving and use of substances at four months post-treatment when compared to treatment as usual (TAU). Witkiewitz and Bowen (2010), in a follow-up study to Bowen et al. (2009), found that individuals in the TAU group showed a strong positive relationship between depression and craving at two months posttreatment, while those in the MBRP group did not demonstrate such a relationship. This study suggests that MBRP altered the commonly found association between depression and craving, such that the relationship no longer existed in individuals who completed MBRP. Finally, in a RCT by Brewer and colleagues (Brewer et al., 2009), MBRP was compared to CBT for a group of alcohol and/or cocaine dependent individuals. While MBRP was utilized in this study, alterations were made to the treatment in order to shorten the sessions to one hour (by decreasing meditation time) and to re-arrange sessions to allow participants to begin treatment as quickly as possible. Results indicated that participants in the MBRP remained in treatment for longer periods of time than those in the CBT group, that both the MBRP and CBT groups rated treatment as highly satisfactory, and that groups did not differ in substance use during treatment. Furthermore, the MBRP group demonstrated decreased stress response according to self-report measures of anxiety following a stress-inducing procedure. These findings suggest that MBRP may be as effective of a substance use intervention as standard CBT regarding actual substance use and may even have additional benefits beyond CBT in managing affect. Thus, while the evidence for MBRP is currently limited to two randomized clinical trials (Bowen et al., 2009; 
Brewer et al., 2009), results are promising in that this intervention may help alleviate symptoms related to substance use, thus further helping prevent relapse.

\section{Summary}

Problematic alcohol use in college student populations is common, and problematic behaviors, such as binge drinking, have been predictive of the development of later alcohol use disorders (Jennison, 2004; Perkins, 2002; SAMHSA, 2011). The Affective Model of Drug Motivation cites that individuals use substances to alleviate NA, allowing them to learn to cope with NA through use, which may serve to strengthen the substance use behavior (Baker et al., 2004). In the laboratory, substance use behaviors have been found to increase upon NA induction (Conklin \& Perkins, 2005; Cooney et al., 1997; Vinci et al., 2012) and are reduced when the individual is allowed to use the substance (Armeli et al., 2003; Kushner, Mackenzie, Fiszdon, Valentiner, \& Foa, 1996). NA is also the primary reason individuals cite for relapse (Kodl et al., 2008; Shiffman et al., 2007; Witkiewitz \& Villarroel, 2011).

Individuals with problematic alcohol use would benefit from strategies specifically aimed at learning better ways to cope with NA when it does occur. Mindfulness-based strategies provide the opportunity for individuals to develop new ways to manage affect by learning to observe unpleasant experiences with a nonjudgmental attitude, while not avoiding the unpleasant experience (Kabat-Zinn, 1994). Such techniques may be particularly applicable to substance users, as using a substance to cope with NA is an avoidance strategy that assists in maintaining problematic use (Baker et al., 2004). Some research has supported brief mindfulness interventions as a way to manage affect (Arch \& Craske, 2006; Ortner et al., 2007) and decrease cigarette use (Bowen \& Marlatt, 2009) in college student samples; however, a brief intervention has not yet been applied to a sample of alcohol users to examine affect and urge response. 
Research to determine if such a brief intervention would be useful to manage NA and urge to drink, especially in problematic college student drinkers, could prove beneficial.

\section{Purposes and Hypotheses of the Present Study}

Specific Aim 1: Determine the effects of a mindfulness intervention on affect response to a NA induction.

Hypothesis 1a: Participants in the Mindfulness + NA Stimuli group will report lower levels of NA than those in the Relaxation + NA Stimuli and Control + NA Stimuli groups, following the affect induction.

Hypothesis 1b: Participants in the Mindfulness + NA Stimuli group will be more likely to endorse willingness to continue watching NA images than those in Relaxation + NA Stimuli and Control + NA Stimuli groups. (Previous research [e.g., Arch \& Craske 2006; Vernig \& Orsillo, 2009] has suggested that response to NA [e.g., a question targeting how they are coping with NA] also be measured in addition to actual level of self-reported affect; this hypothesis attempts to address this area.)

Specific Aim 2: Determine the effects of a mindfulness intervention on urge to drink following the NA induction.

Hypothesis 2a: Participants in the Mindfulness + NA Stimuli group will report decreases in urge to drink when compared to those in the Relaxation + NA Stimuli and Control + NA Stimuli groups post-affect induction.

Hypothesis 2b: Participants in the Relaxation + NA Stimuli and Control + NA Stimuli groups will report wanting to have an alcoholic beverage sooner than those in the Mindfulness + NA Stimuli group post-affect induction. 


\section{METHOD}

\section{Participants}

Participants were college students reporting problematic drinking (defined as a score of six or higher on the AUDIT) and endorsement of enhancement and/or coping motives for drinking (defined by having an elevated score on the Enhancement and/or Coping Motives subscales of the Drinking Motives Questionnaire-Revised [DMQ-R] when compared to the other subscales). Eligibility was determined through an initial screening, and eligible participants were invited to attend the intervention phase. All participants received course credit for their participation. Volunteers were recruited via flyers on campus and through a social media website; they did not receive compensation. For the present study, a total of 217 participants (36 in each group) needed to be recruited in order to obtain a medium effect size (based on Cohen's d) with a power of .80 and alpha level of .05 (calculated with $\mathrm{G}^{*}$ power; Faul, Erdfelder, Lang, \& Buchner, 2007; effect size based on Bowen \& Marlatt, 2009 and Vernig \& Orsillo, 2009).

\section{Materials}

Demographic Questionnaire. Demographic information including gender, race, ethnicity, education level, and relationship status was gathered with this form developed by the experimenter.

Alcohol Use Disorders Identification Test (AUDIT; Babor, Higgins-Biddle, Saunders, \& Monteiro, 2001). The AUDIT is a 10-item self-report measure used to assess potentially hazardous or harmful alcohol use. Each question is rated on a Likert scale of 0 (indicating less frequency of behavior) to 4 (increased frequency), and total scores are obtained from calculating the sum of responses, ranging from 0 - 40. Individuals who score eight or higher in the general population are likely engaging in hazardous drinking behaviors (Saunders et al., 1993). College 
students have a cut-off score ranging from 6-8 regarding hazardous drinking (Fleming, Barry, \& MacDonald, 1991; Kokotailo et al., 2004); thus, the cut-off score of 6 was used in the present study to determine participant eligibility. The AUDIT has demonstrated good test-retest reliability $(r=.86)$, good concurrent validity $(r=.78-.88)$, and decent predictive validity regarding global life functioning, alcohol-related physical and social problems, and hazardous drinking (Babor et al., 2001). The AUDIT yielded adequate internal consistency $(r=.64)$ for eligible participants in the present study.

Drinking Motives Questionnaire-Revised (DMQ-R; Cooper, 1994). The DMQ-R is a 20-item self-report measure assessing four drinking motives-Enhancement, Coping, Social Affiliative, and Social Conformity. Participants rate each item from 1 (never) to 5 (almost always). The present study screened for those endorsing the Enhancement and/or Coping facets as their primary drinking motives, as individuals who endorse these motives often cite drinking to alter their emotional state (i.e., to increase PA or to decrease NA). The DMQ-R has been validated in a college sample and has demonstrated high internal consistency $(r=.81-.94$, depending on subscale; MacLean \& Lecci, 2000) and good predictive validity of heavy drinking and drinking problems (Cooper, 1994). Eligible participants in the current study yielded the following internal consistency scores for each subscale: Enhancement $(r=.84)$, Coping $(r=.83)$, Social Affiliative $(r=.62)$, and Social Conformity $(r=.84)$.

The Five-Factor Mindfulness Questionnaire (FFMQ; Baer et al., 2006). The FFMQ is a 39-item measure assessing five facets of mindfulness from 1 (never or rarely true) to 5 (very often or always true). This questionnaire was developed by combining questions from other measures used to assess mindfulness. Following a factor analysis, five factors emerged, which are assessed using the FFMQ: Observing, Describing, Acting with Awareness, Nonjudging, and 
Nonreactivity. This measure was used in the current study to assess participants' general degree of mindfulness. Psychometric properties of FFMQ have been examined in college students and have demonstrated good internal consistency ( $r=.70-.90$, depending on subscale) in this population. The FFMQ has also demonstrated moderate concurrent validity $(r=.42-.68)$ and good predictive validity of psychological symptoms (Baer et al., 2006). The present study found the following internal consistency estimates for each subscale: Observing $(r=.70)$, Describing $(r$ $=.91)$, Acting with Awareness $(r=.87)$, Nonjudging $(r=.87)$, and Nonreactivity $(r=.71)$.

The Toronto Mindfulness Scale (TMS; Lau et al., 2006) is a 13-item self-report measure of state mindfulness, scored from 0 (not at all) to 5 (very much). Primarily, mindfulness measures assess inter-individual differences in trait mindfulness. However, Lau et al. (2006) posit that mindfulness may differ on an intra-individual level over time, and the TMS was developed as a measure of state mindfulness at a given moment in time. The TMS yields two factors: "Curiosity" (awareness of the present moment, with the approach of curiosity) and "Decentering" (noticing feelings and thoughts, while maintaining distance from them). The measure shows good internal consistency $(r=.95)$ and post-treatment predictive validity regarding stress and psychological symptoms (Lau et al., 2006). The TMS was used in the present study as a manipulation check, in order to verify that the mindfulness instructions increased state mindfulness. Prior research has found that participants with no previous experience in mindfulness meditation are capable of applying such practices in the laboratory following brief mindfulness instructions on how to do so (Thompson \& Waltz, 2007). Baseline internal consistency estimates for the present study were as follows: Curiosity $(r=.85)$ and Decentering $(r=.65)$. 
Positive and Negative Affect Schedule (PANAS; Watson et al., 1988). The PANAS is a 20-item self-report measure that assesses an individual's PA and NA at a given point in time. Twenty different emotions are listed, and individuals rate items from 1 (very slightly or not at all) to 5 (extremely). The PANAS has shown good internal consistency $(r=.86-.90$ for PA and $r$ $=.84-.87$ for NA) and moderate concurrent validity $(r=.51-.74$; Watson et al., 1988). The present study utilized the PANAS at baseline, as well as at pre- and post-affect induction. Baseline reliability estimates in the present study were $r=.84$ for PA and $r=.70$ for NA.

Urge to Drink. A single-item question on a 10-point Likert scale was used to assess participant urge to drink in that moment. Participants indicated their urge from 1 (absolutely no urge) to 10 (very strong urge). Single-item measures such as this have been found to be both reliable and valid in assessing an individual's urge to drink (Monti, Rohsenow, \& Hutchison, 2000).

Tension/Relaxation. Participants' level of tension/relaxation was assessed with a singleitem question, asking them to indicate the level of their tension at that moment on a 10-point Likert scale. Participants rated their tension from 1 (absolutely no tension) to 10 (extremely tense).

International Affective Picture System (IAPS; Lang, Bradley, \& Cuthbert, 2005). Images from IAPS were utilized for the mood induction procedure. IAPS provides a set of standardized, color photographs that induce a particular emotion within the individual viewing them. The current study presented individuals with pictures inducing NA and neutral affect. The selected pictures were taken from a study by Conklin and Perkins (2005), who conducted extensive pilot work to determine which pictures consistently produced these responses. Conklin and Perkins also utilized music to induce particular moods. Those musical selections that 
corresponded to the given mood (NA or neutral) were also used in the present study. The mood induction procedure in the present study consisted of presenting participants with 14 images, shown for 20 seconds each (lasting for a total of approximately five minutes), while listening to music corresponding with affect condition. A brief affect manipulation such as this has been found to significantly elevate NA from baseline in college student smokers (Vinci et al., 2012).

Mindfulness intervention. Participants in the mindfulness condition listened to a 10minute guided meditation instructing them to focus on the present moment, specifically noting their breath and other sensations that may be occurring (e.g., sounds, sights, touch; see Appendix A). They were instructed to do this with an attitude of nonjudgment and acceptance. The tape recording utilized by Adams et al. (2013) was replicated and utilized in the present study. Results from that study indicated that those who listened to the mindfulness tape significantly increased in level of state mindfulness compared to the group that did not listen to the tape. This intervention was primarily adapted of excerpts from Kabat-Zinn (1994, 2002); the five facets of mindfulness (Baer et al., 2006) were also incorporated throughout.

Relaxation intervention. Participants in the relaxation intervention listened to a 10minute tape instructing them to physically relax their body (see Appendix B). This intervention was considered a passive progressive muscle relaxation (Feldman et al., 2010), as participants were not instructed to initially tense each muscle. The tape first asked participants to take several deep breaths. Next, participants were guided through each muscle group and asked to relax it. The instructions for this intervention were adapted from Bernstein and Borkovec (1973) and Antoni (2003). 


\section{Procedure}

All study procedures were approved by the University's Institutional Review Board (IRB). College student drinkers were recruited for the initial screening session of the study. Participants registered for the experiment through the Psychology Department's Experiment Website. Data for the screening phase was collected and stored through a secure online survey engine, SONA. Participants read and indicated their consent to participate in the study and to complete the online questionnaires: the demographic form, the AUDIT, and the DMQ-R. Participants were then asked if they would be interested in the second phase of the study. The email address of interested participants was then obtained in order to be contacted for the second part of the experiment. Participants who met the eligibility criteria (i.e., an AUDIT score of six and above and endorsement of drinking primarily for Enhancement and Coping Motives on the DMQ-R) were then invited to participate in the experiment via email by the study coordinator. Interested participants were scheduled for the experimental session within one to two weeks after they responded to the email.

Those participants recruited through flyers and social media initially contacted the study coordinator via email indicating their interest in the study. After being provided with information about the study, those who were interested were scheduled to participate. Volunteers completed the screening measures in-person and if deemed eligible, completed the experimental portion of the experiment at that time.

The experimental phase of the study took place between the hours of 3:00 PM and 8:00 PM, Monday through Friday. Participants first completed the FFMQ. They were then brought into an individual room for the rest of the experiment. At this point, participants were randomly assigned (via a random number table) to one of six experimental groups: Mindfulness 
Intervention + NA Stimuli, Relaxation Intervention + NA Stimuli, Control + NA Stimuli, Mindfulness Intervention + Neutral Stimuli, Relaxation Intervention + Neutral Stimuli, or Control + Neutral Stimuli. The experiment consisted of six phases (see Figure 1 for flowchart of study procedures):

Phase 1: Pre-manipulation questionnaires at Time 1 (T1). Participants completed the PANAS, TMS, the single-item question assessing tension/relaxation, and the single-item question assessing urge to drink.

Phase 2: Mindfulness/Relaxation manipulation. Participants in the mindfulness and relaxation conditions underwent their respective interventions. Those in the control condition completed a word search puzzle for 10 minutes, in order to control for any time effects.

Phase 3: Post-mindfulness questionnaires at Time 2 (T2). All participants completed the PANAS, TMS, single-item tension/relaxation question, and the single-item urge question.

Phase 4: Affect manipulation. Instructions for the affect induction were then read, explaining that participants should allow themselves to feel whatever emotions came upon them while watching the images (see Appendix C). Participants in the mindfulness and relaxation conditions were given additional instructions, asking them to apply the guided skills they just listened to, when viewing the images. Those participants in the control group were given no additional instructions. Those in the NA group then underwent the NA induction, while those in the neutral group underwent the neutral mood induction.

Phase 5: Post-affect questionnaires at Time 3 (T3). All participants completed the PANAS, single-item tension/relaxation question, and single-item urge question. Participants were also asked how much they would be willing to continue watching the images and rated their response on a 10-point Likert scale. Regardless of response, participants did not actually watch 


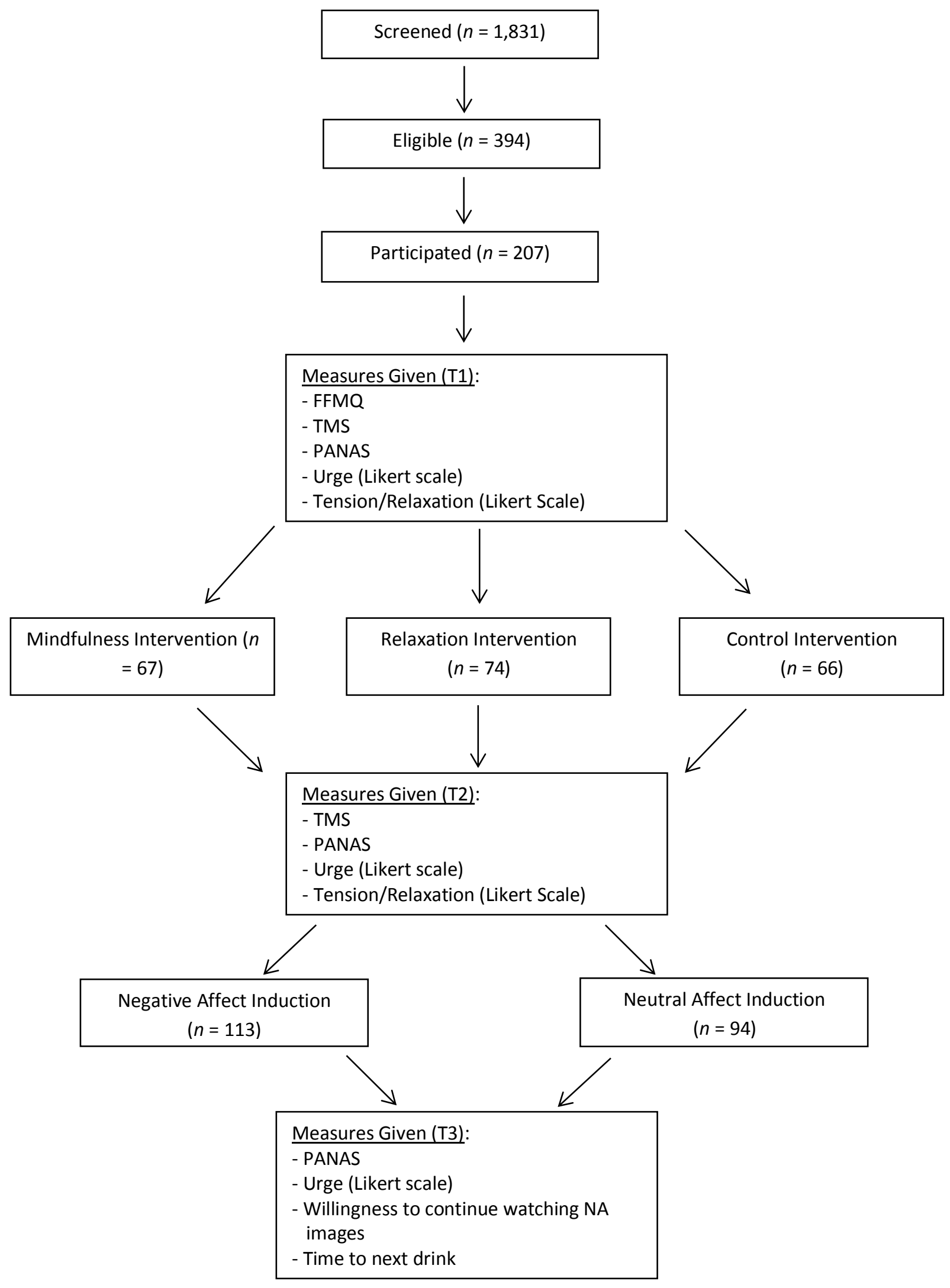

Figure 1. Flowchart of study procedures 
more images. Participants were also asked to indicate the next time they planned to have an alcoholic beverage; hours until next drink were documented.

Phase 6: Debriefing. Anyone inquiring about the purpose of the study was provided with additional information at this time. 


\section{RESULTS}

A total of 1,831 participants were screened for the study and 394 were deemed eligible to participate in the experimental portion. All 394 eligible participants were invited to participate in the experimental session. Two hundred and seven of these participants responded to the invitation and participated in the study. Independent samples $t$-tests and a chi square analysis were conducted to determine if those who were eligible and participated were different from those who were eligible and did not participate on age, AUDIT score, and gender. Results of the independent samples $t$-test revealed no difference between groups on age, $t(381)=-1.06, p=.29$ or AUDIT score, $t(389)=-.48, p=.63$. Results of the chi square analysis of gender also indicated that males and females were equally distributed between the groups, $\chi^{2}(1)=.37, p=$ .54 .

Of the 207 participants who participated, 96.1\% participated for course credit and 3.9\% volunteered. The average age was $20.13(S D=1.89)$ and $76.3 \%$ of participants were women. Participants identified as 85.5\% Caucasian, 6.3\% African American, 3.5\% Hispanic, 2.4\% Mixed Race, 1.4\% American Indian, and 1\% Asian. The average AUDIT score was $10.03(S D=4.28)$. Average scores on the DMQ-R subscales were as follows: Enhancement $=3.35(S D=.97)$, Coping $=1.84(S D=.85)$, Social Affiliation $=1.17(S D=.33)$, and Social Conformity $=2.77$ $(S D=.91)^{3}$. Random assignment to the six experimental groups resulted in the following group sizes: Mindfulness + NA Stimuli: $n=39$, Mindfulness + Neutral Stimuli: $n=28$, Relaxation + NA Stimuli: $n=35$, Relaxation + Neutral Stimuli: $n=39$, Control + NA Stimuli: $n=39$, and Control + Neutral Stimuli: $n=27($ see Table 1).

\footnotetext{
${ }^{3}$ Very few participants elevated on the Coping motive to meet eligibility criteria, as most elevated on Enhancement. This being the likely reason that the average score on Social Conformity (which was not part of the inclusion criteria) was elevated more than Coping.
} 
Table 1

Participant Distribution in Groups.

\begin{tabular}{|l|c|c|c|c|}
\hline & Mindfulness Intervention & Relaxation Intervention & Control & Total \\
\hline NA Stimuli & 39 & 35 & 39 & 113 \\
\hline Neutral Stimuli & 28 & 39 & 27 & 94 \\
\hline Total & 67 & 74 & 66 & 207 \\
\hline
\end{tabular}

Preliminary one-way analyses of variance (ANOVAs) were conducted to determine if any baseline differences emerged between the groups on the continuous variables of age, AUDIT score, FFMQ subscales, PANAS NA, PANAS PA, TMS subscales, urge to drink, and physical relaxation (see Table 2 for means and SDs). The only significant difference between groups emerged on the PANAS NA, $F(5,206)=2.6, p=.03$. However, post hoc analyses revealed that no significant differences existed between any groups. Chi square analysis of gender indicated that there was not a significant difference between the proportion of males and females in the groups.

\section{Manipulation Checks}

Paired sample $t$-tests and one-way ANOVAs were conducted to confirm that the mindfulness and relaxation interventions were effective, as well as the NA mood induction manipulation.

Mindfulness intervention. Paired sample $t$-tests were first utilized to determine whether the Mindfulness groups significantly increased in level of mindfulness (according to TMS subscale scores) from T1 (pre-intervention) to T2 (post-intervention). Results indicated that TMS 
Table 2

Means and SDs at Baseline for each Group.

\begin{tabular}{|l|c|c|c|c|c|c|c|}
\hline & Age & AUDIT & $\begin{array}{c}\text { FFMQ } \\
\text { Observe }\end{array}$ & $\begin{array}{c}\text { FFMQ } \\
\text { Describe }\end{array}$ & $\begin{array}{c}\text { FFMQ Acting } \\
\text { with Awareness }\end{array}$ & $\begin{array}{c}\text { FFMQ } \\
\text { Nonjudge }\end{array}$ & $\begin{array}{c}\text { FFMQ } \\
\text { NonReact }\end{array}$ \\
\hline Mindful + NA & $20.15(1.35)$ & $10.08(3.67)$ & $3.15(.62)$ & $3.64(.76)$ & $3.12(.73)$ & $3.37(.59)$ & $2.92(.54)$ \\
\hline Mindful + NE & $20.38(1.94)$ & $9.11(3.18)$ & $3.26(.59)$ & $3.64(.73)$ & $3.21(.73)$ & $3.56(.89)$ & $2.93(.59)$ \\
\hline Relax + NA & $19.94(1.48)$ & $10.63(5.45)$ & $3.28(.56)$ & $3.22(.71)$ & $2.94(.73)$ & $3.30(.76)$ & $2.93(.42)$ \\
\hline Relax + NE & $20.46(2.81)$ & $10.00(5.05)$ & $3.25(.49)$ & $3.27(.77)$ & $2.93(.69)$ & $3.20(.71)$ & $2.87(.52)$ \\
\hline Control + NA & $20.05(1.52)$ & $10.13(3.49)$ & $3.38(.69)$ & $3.53(.66)$ & $3.14(.59)$ & $3.18(.82)$ & $3.06(.52)$ \\
\hline Control + NE & $19.70(1.86)$ & $10.04(4.42)$ & $3.13(.58)$ & $3.60(.87)$ & $3.08(.66)$ & $3.19(.73)$ & $3.00(.76)$ \\
\hline$p$ value & .44 & .11 & .32 & .70 & .86 & .22 & .17 \\
\hline
\end{tabular}

\begin{tabular}{|l|c|c|c|c|c|c|}
\hline & PANAS NA & PANAS PA & $\begin{array}{c}\text { TMS } \\
\text { Curiosity }\end{array}$ & $\begin{array}{c}\text { TMS } \\
\text { Decentering }\end{array}$ & Urge & Tension/Relaxation \\
\hline Mindful + NA & $14.87(4.70)$ & $26.62(7.64)$ & $13.82(3.86)$ & $13.44(4.04)$ & $2.62(1.82)$ & $3.62(1.84)$ \\
\hline Mindful + NE & $12.50(2.25)$ & $28.86(6.43)$ & $14.96(4.69)$ & $12.64(4.50)$ & $2.50(2.05)$ & $2.93(1.72)$ \\
\hline Relax + NA & $12.91(2.32)$ & $27.09(6.05)$ & $14.09(4.45)$ & $12.91(3.91)$ & $3.00(2.18)$ & $3.71(2.11)$ \\
\hline Relax + NE & $14.95(3.96)$ & $27.15(5.73)$ & $13.28(4.85)$ & $12.26(4.20)$ & $3.08(2.04)$ & $3.64(1.99)$ \\
\hline Control + NA & $13.90(3.59)$ & $27.97(6.18)$ & $13.97(4.76)$ & $13.49(4.53)$ & $2.64(1.80)$ & $3.44(2.26)$ \\
\hline Control + NE & $13.96(3.73)$ & $25.56(5.91)$ & $15.78(4.30)$ & $13.37(4.30)$ & $2.81(1.96)$ & $3.11(2.41)$ \\
\hline$p$ value & .03 & .70 & .61 & .95 & .94 & .69 \\
\hline
\end{tabular}

Note. $\mathrm{NE}=$ Neutral Affect. Standard deviations in parentheses. 
scores for both Curiosity and Decentering significantly increased from T1 to T2, $t(66)=-3.62, p$ $=.001$ and $t(66)=-7.57, p=.001$, respectively (see Table 3 for means and SDs). Paired sample $t$-tests were also examined for any changes for the Relaxation and Control groups from T1 to T2. Results indicated a significant increase for the Relaxation group in Decentering from T1 to T2, $t(73)=2.66, p=.01$. No other group differences were found from T1 to T2 for the Relaxation or Control groups. Given that the Decentering subscale measures an individual's ability to distance oneself from thoughts, feelings, and physical sensations, it is possible that the relaxation intervention targeted some of these areas.

Table 3

Manipulation Check Means and Standard Deviations for Changes in Mindfulness from T1 to T2.

\begin{tabular}{|l|c|c|c|c|}
\hline & $\begin{array}{c}\text { TMS Curiosity } \\
\text { at T1 }\end{array}$ & $\begin{array}{c}\text { TMS Curiosity } \\
\text { at T2 }\end{array}$ & $\begin{array}{c}\text { TMS Decentering } \\
\text { at T1 }\end{array}$ & $\begin{array}{c}\text { TMS Decentering } \\
\text { at T2 }\end{array}$ \\
\hline $\begin{array}{l}\text { Mindfulness } \\
\text { Group }\end{array}$ & $14.30(4.23)$ & $16.00(3.89)$ & $13.10(4.23)$ & $16.63(3.44)$ \\
\hline $\begin{array}{l}\text { Relaxation } \\
\text { Group }\end{array}$ & $13.66(4.65)$ & $13.01(5.03)$ & $12.57(4.06)$ & $14.05(4.90)$ \\
\hline Control Group & $14.71(4.63)$ & $14.05(5.18)$ & $13.44(4.40)$ & $14.02(5.06)$ \\
\hline
\end{tabular}

Note. Standard deviations in parentheses.

To examine the effectiveness of the mindfulness intervention compared to the other interventions at T2, a one-way ANOVA was utilized with intervention type (Mindfulness vs. Relaxation vs. Control) entered as the independent variable (IV) and TMS subscales scores (Curiosity and Decentering) as the dependent variables (DV). Results indicated that Curiosity significantly differed between groups following the mindfulness intervention (at T2), $F(2,206)=$ $7.11, p=.001$. Bonferroni post hoc testing revealed that the Mindfulness group had significantly higher Curiosity scores than the Relaxation group, $p=.001$. Differences between the Mindfulness group and Control group approached significance, $p=.056$. For the Decentering 
subscale, groups also significantly differed following the mindfulness intervention, $F(2,206)=$ $7.39, p=.001$. Post hoc testing revealed that the Mindfulness group had significantly higher scores in Decentering compared to the Relaxation, $p=.003$ and Control, $p=.003$ groups.

Overall, these findings indicate that the mindfulness intervention was effective at increasing state mindfulness for the Mindfulness group, above and beyond that of the Relaxation and Control groups. See Figures 2 and 3.

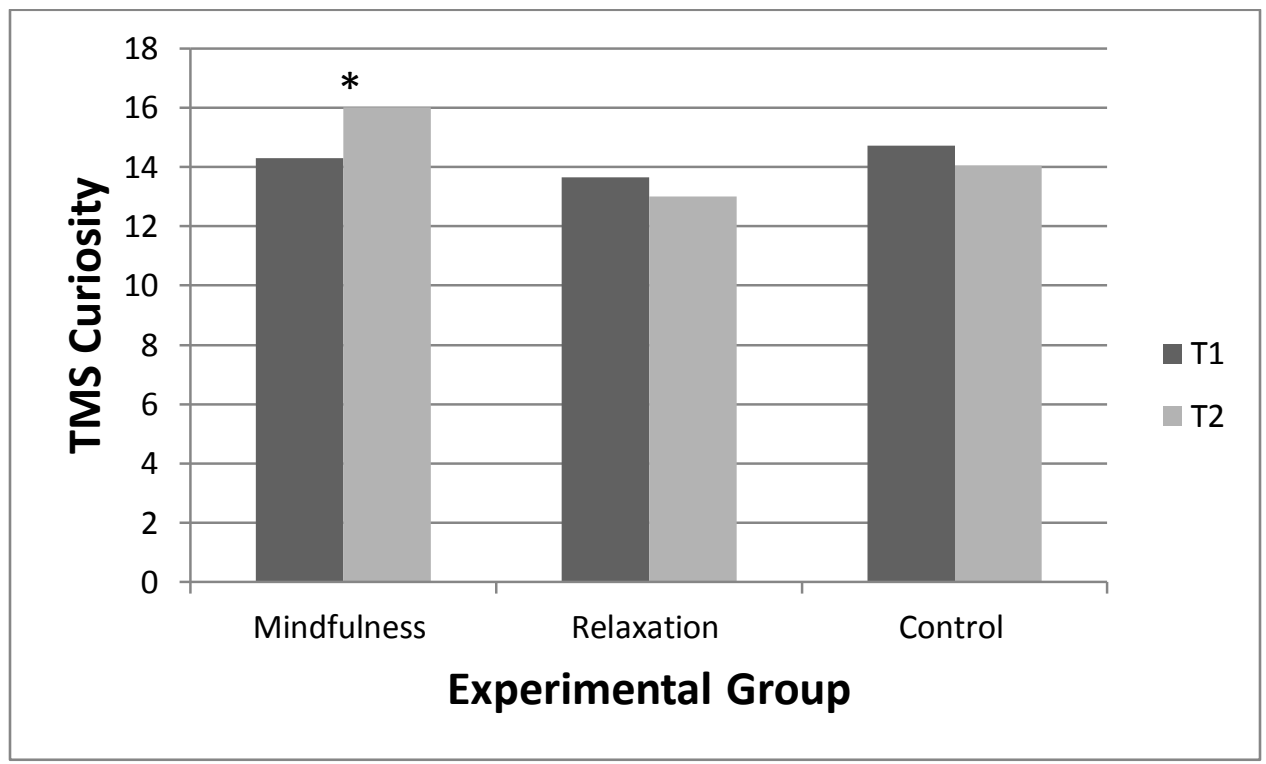

Figure 2. TMS curiosity ratings pre- and post-interventions (T1 vs T2).

Note: * indicates significant changes from T1 to T2 for that group. 


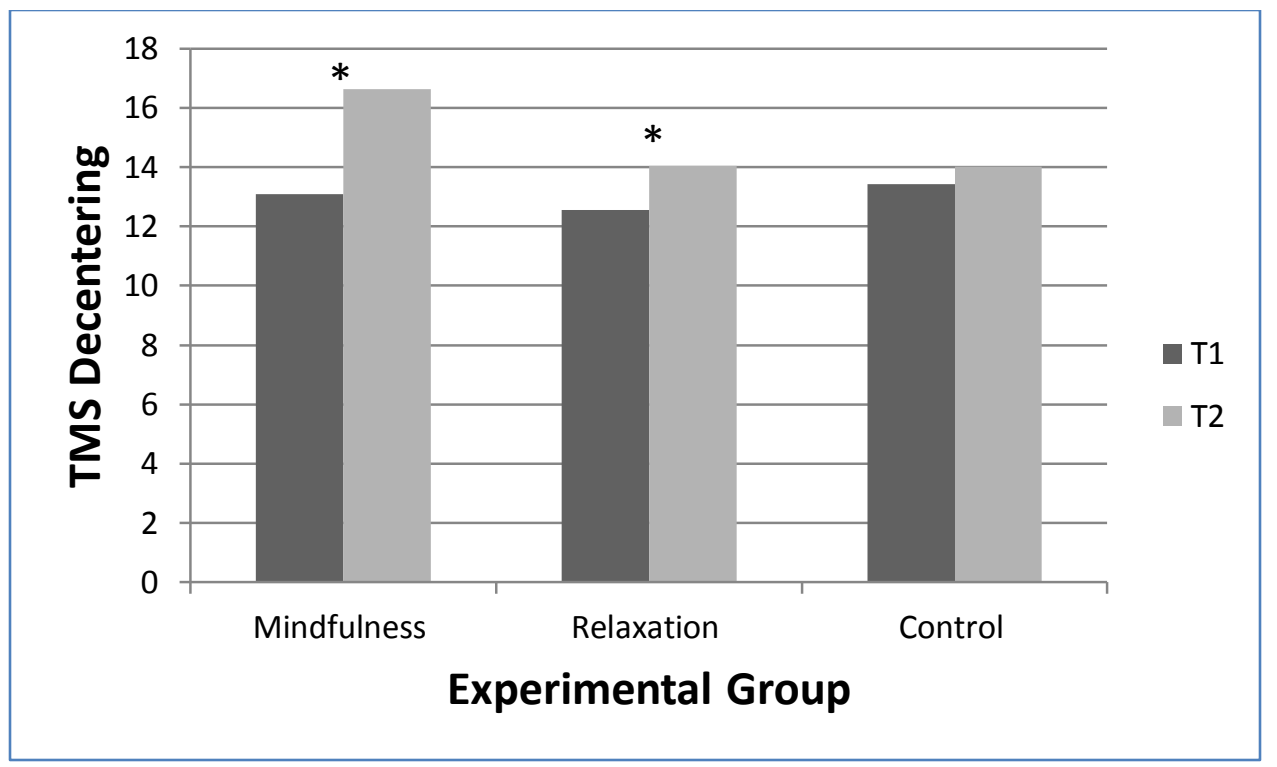

Figure 3. TMS decentering ratings pre- and post-interventions (T1 vs T2). Note: * indicates significant changes from T1 to T2 for that group.

Physical relaxation intervention. Similar analyses were conducted to determine whether the physical relaxation intervention was effective at increasing relaxation for the Relaxation group. The Likert scale measure assessing level of relaxation (from 1 - 10) was used, with lower scores representing increased levels of relaxation and higher scores indicating increased tension. Paired sample $t$-tests revealed that the Relaxation group significantly increased in level of relaxation from $\mathrm{T} 1$ to $\mathrm{T} 2, t(72)=8.12, p=.001$. The Mindfulness group also significantly increased from $\mathrm{T} 1$ to $\mathrm{T} 2, t(65)=4.08, \mathrm{p}=.001$. The Control group did not have any significant changes from T1 to T2 (see Table 4 for all means and SDs).

A one-way ANOVA was conducted to determine the effectiveness of the physical relaxation intervention at $\mathrm{T} 2$, with intervention type as the IV and physical relaxation score as the DV. Results indicated that groups significantly differed on level of relaxation following the 
Table 4

Manipulation Check Means and Standard Deviations for Changes in Relaxation from T1 to T2.

\begin{tabular}{|l|c|c|}
\hline & $\begin{array}{c}\text { Tension/Relaxation } \\
\text { at T1 }\end{array}$ & $\begin{array}{c}\text { Tension/Relaxation } \\
\text { at T2 }\end{array}$ \\
\hline Mindfulness Group & $3.33(1.83)$ & $2.50(1.78)$ \\
\hline Relaxation Group & $3.68(2.05)$ & $2.23(1.57)$ \\
\hline Control Group & $3.34(2.31)$ & $3.32(1.90)$ \\
\hline
\end{tabular}

Note. Standard deviations in parentheses. Lower numbers indicate higher levels of relaxation.

intervention (at T2), $F(2,203)=7.14, p=.001$. Bonferroni post hoc testing revealed that the Mindfulness group had higher levels of relaxation than the Control group, $p=.023$. The Relaxation group also had significantly higher levels of relaxation than the Control group, $p=$ .001. The Relaxation and Mindfulness groups' similarity on relaxation is consistent with the theory and purpose of mindfulness interventions, which are intended to produce relaxation as well as increased levels of mindfulness. Overall, these results indicate the physical relaxation intervention was effective at significantly increasing level of relaxation for the Relaxation and Mindfulness groups, above and beyond that of the Control group. See Figure 4.

Affect manipulation. Paired sample $t$-tests were utilized to determine whether the NA induction was effective at increasing level of NA, according to the PANAS. Given that the NA induction occurred after the mindfulness and relaxation interventions, the Control groups' responses to the NA induction were examined. Results indicated that the NA group significantly increased in level of NA from T2 (pre-NA induction) to T3 (post-NA induction), $t(38)=-6.41, p$ $=.001$. Examination of the neutral affect group revealed that following the neutral induction, NA significant decreased from T2 to T3, $t(26)=2.60, p=.02$ (see Table 5 for all means and SDs). 


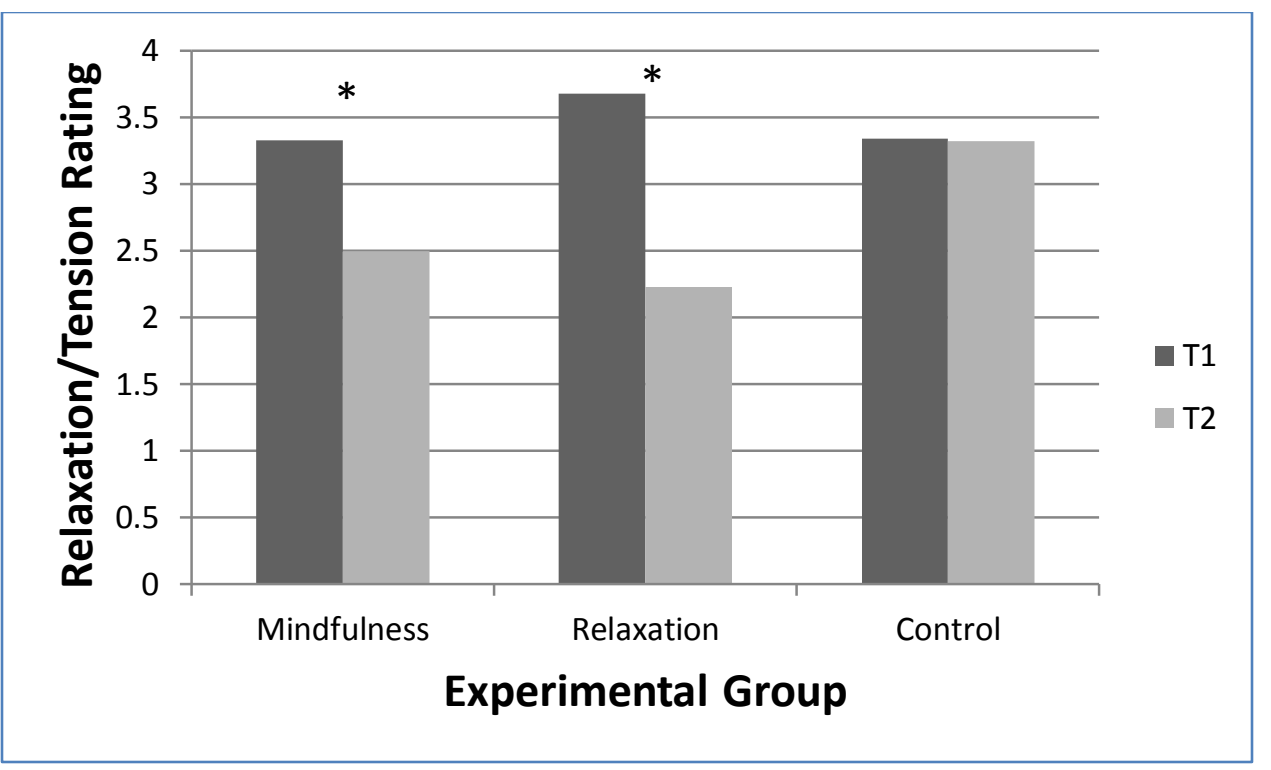

Figure 4. Relaxation/Tension ratings pre- and post-interventions (T1 vs T2).

Note: * indicates significant change from T1 to T2 for that group.

Table 5

Manipulation Check Means and Standard Deviations for Changes in NA from T2 to T3.

\begin{tabular}{|l|c|c|}
\hline & $\begin{array}{c}\text { PANAS NA } \\
\text { at T2 }\end{array}$ & $\begin{array}{c}\text { PANAS NA } \\
\text { at T3 }\end{array}$ \\
\hline Control + NA & $13.05(3.09)$ & $20.67(7.78)$ \\
\hline Control + Neutral & $12.89(2.76)$ & $11.78(2.28)$ \\
\hline
\end{tabular}

Note. Standard deviations in parentheses.

One-way ANOVAs were then conducted to determine whether those in the Control group who underwent the NA induction significantly increased in NA when compared to the Control group who underwent the neutral induction. For both T2 and T3, affect induction type (NA or neutral) was the IV and NA score was the DV. Results indicated that groups did not differ significantly prior to the affect induction (at T2), $F(1,65)=.05, p=.827$, which was expected. They did significantly differ following the affect induction (at T3), $F(1,65)=33.10, p=.001$, 
with the NA group reporting higher NA scores than the neutral group. These results indicate the NA induction was effective at increasing NA, above and beyond that of the neutral induction group. See Figure 5.

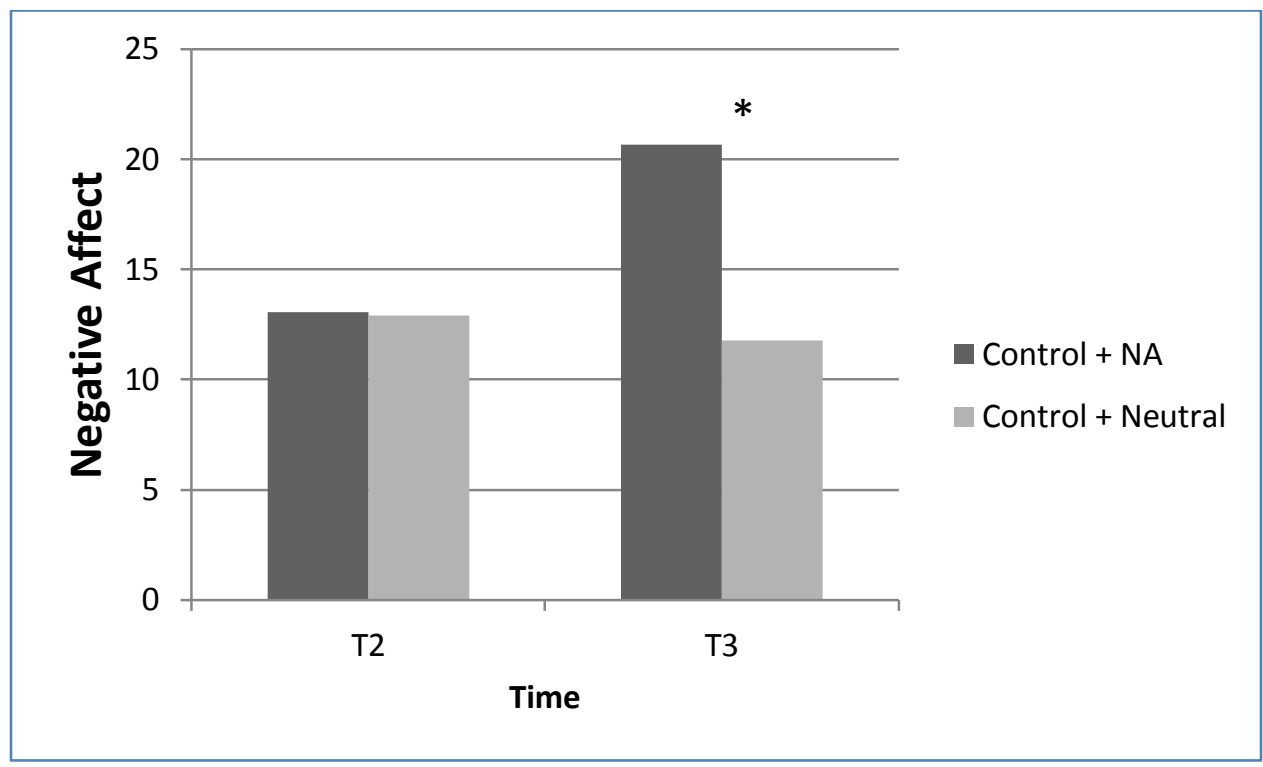

Figure 5. NA ratings pre- and post-affect induction (T2 vs T3).

Note: * indicates significant group differences

\section{Primary Analyses ${ }^{4}$}

Hypotheses 1a and 2a. Given there were multiple assessments of PANAS NA and Urge at T1, T2, and T3 (which was not the case for the DVs of Images and Time to Next Drink), a repeated measures multivariate analysis of variance (MANOVA) was conducted on these two variables. Group (Mindfulness + NA Stimuli, Relaxation + NA Stimuli, Control + NA Stimuli) and Time (T1, T2, T3) were entered in as the IVs and PANAS NA and Urge scores as the DVs.

\footnotetext{
${ }^{4}$ Given that baseline levels of PANAS NA were different according to the one-way ANOVA, all primary analyses were conducted covarying this variable; however, holding PANAS NA levels constant did not change the significance level of the results. Thus, data are presented here without covarying PANAS NA. Further, the day of the week that participants completed the experiment could have impacted their responses (e.g., a Monday versus Friday participant). Thus, this variable was also initially held constant to make sure it did not impact the results. However, results did not change; therefore, this variable was also not covaried in the analyses presented here.
} 
Results indicated no main effect of Group $[F(4,107)=1.25, p=.29]$, a significant main effect of Time $[F(4,214)=45.16, p=.001]$, and a significant interaction for Group and Time $[F(8,210)=$ $2.28, p=.024]$. Follow-up repeated measure MANOVAs were conducted to examine each separate time effect (T1 to T2 and T2 to T3) for both PANAS NA and Urge and indicated the following: from $\mathrm{T} 1$ to $\mathrm{T} 2$, there was a significant effect of Group, $F(4,216)=3.16, p=.015$, Time, $F(2,107)=27.77, p=.001$, and Interaction of Group and Time, $F(4,214)=4.26, p=.002$. From T2 to T3, there was a nonsignificant effect of Group, $F(4,214)=1.24, p=.295$, a significant effect of Time, $F(2,107)=88.15, p=.001$, and a nonsignificant interaction of Group and Time $F(4,214)=.34, p=.854$.

Examination of the interaction effect from $\mathrm{T} 1$ to $\mathrm{T} 2$ revealed that PANAS NA scores were significant, $F(2,108)=6.58, p=.002$, while Urge scores were not $F(2,108)=2.4, p=.10$. In order to follow up the significant PANAS NA result, one-way ANVOAs were conducted (with Group as the IV and PANAS NA T1 and PANAS NA T2 scores as the DVs). Significant differences emerged at PANAS NA T2, $F(2,112)=12.86, p=.001$. Bonferroni post hoc testing indicated that the Mindfulness + NA Stimuli group significantly decreased in NA more than the Control + NA Stimuli group, $p=.005$. The Relaxation + NA Stimuli group also decreased in NA more than the Control + NA Stimuli group, $p=.001$. Paired sample t-tests examined any changes across time from T1 to T2 for each group. Results indicated that the Mindfulness + NA and Relaxation + NA groups significantly decreased in NA, $t(38)=4.45, p=.001$ and $t(34)=6.31, p$ $=.001$, respectively (see Table 6 for means and SDs). These findings suggest that NA decreased more so for the Mindfulness and Relaxation groups following the mindfulness and relaxation interventions at $\mathrm{T} 2$ than those in the Control group. 
Table 6

NA and Urge Estimated Marginal Means and Standard Errors for Each Group Across Time.

\begin{tabular}{|l|c|c|c|c|c|c|}
\hline & \multicolumn{3}{|c|}{ PANAS NA } & \multicolumn{3}{c|}{ Urge } \\
\hline & T1 & T2 & T3 & T1 & T2 & T3 \\
\hline $\begin{array}{l}\text { Mindfulness } \\
+ \text { NA }\end{array}$ & $15.00(.60)$ & $11.37(.35)$ & $\begin{array}{c}19.66 \\
(1.13)\end{array}$ & $2.53(.31)$ & $2.29(.30)$ & $2.74(.32)$ \\
\hline $\begin{array}{l}\text { Relaxation } \\
+ \text { NA }\end{array}$ & $12.91(.63)$ & $10.51(.37)$ & $\begin{array}{l}19.74 \\
(1.17)\end{array}$ & $3.00(.32)$ & $2.51(.32)$ & $3.06(.34)$ \\
\hline $\begin{array}{l}\text { Control + } \\
\text { NA }\end{array}$ & $13.92(.60)$ & $13.11(.35)$ & $\begin{array}{l}20.82 \\
(1.13)\end{array}$ & $2.68(.31)$ & $2.66(.30)$ & $2.95(.32)$ \\
\hline
\end{tabular}

Note. Standard errors in parentheses.

Examination of the significant main effect of Time from T2 to T3 indicated a significant effect for PANAS NA, $F(1,108)=177.55, p=.001$ and Urge, $F(1,108)=13.29, p=.001$. As with the previously reported findings, follow-up one way ANOVAs were conducted on each significant DV (PANAS NA and Urge) but at T2 and T3. For PANAS NA, significant group differences emerged at $\mathrm{T} 2$, which duplicate those findings in the above paragraph at $\mathrm{T} 2$. No significant differences emerged at T2 between groups for Urge; no significant differences emerged at T3 for PANAS NA or Urge. Paired sample t-tests examined any changes across time from T2 to T3 for each group on PANAS NA and Urge. For PANAS NA all the groups significantly increased from T2 to T3, Mindfulness $+\mathrm{NA}[t(38)=-8.68, p=.001]$, Relaxation + $\mathrm{NA}[t(34)=-8.59, p=.001]$ and Control $+\mathrm{NA}[t(38)=-6.41, p=.001]$. For Urge, the Mindfulness + NA $[t(37)=-2.21, p=.03]$ and Relaxation + NA [t(34) $=-2.33, p=.003]$ groups significantly increased.

Overall, these results do not support the hypotheses 1a or 2a, proposing that NA and Urge would decrease following the NA induction (from T2 to T3) for those who underwent the 
mindfulness intervention (versus the relaxation intervention or control group; see Figures 6 and 7 for NA and Urge).

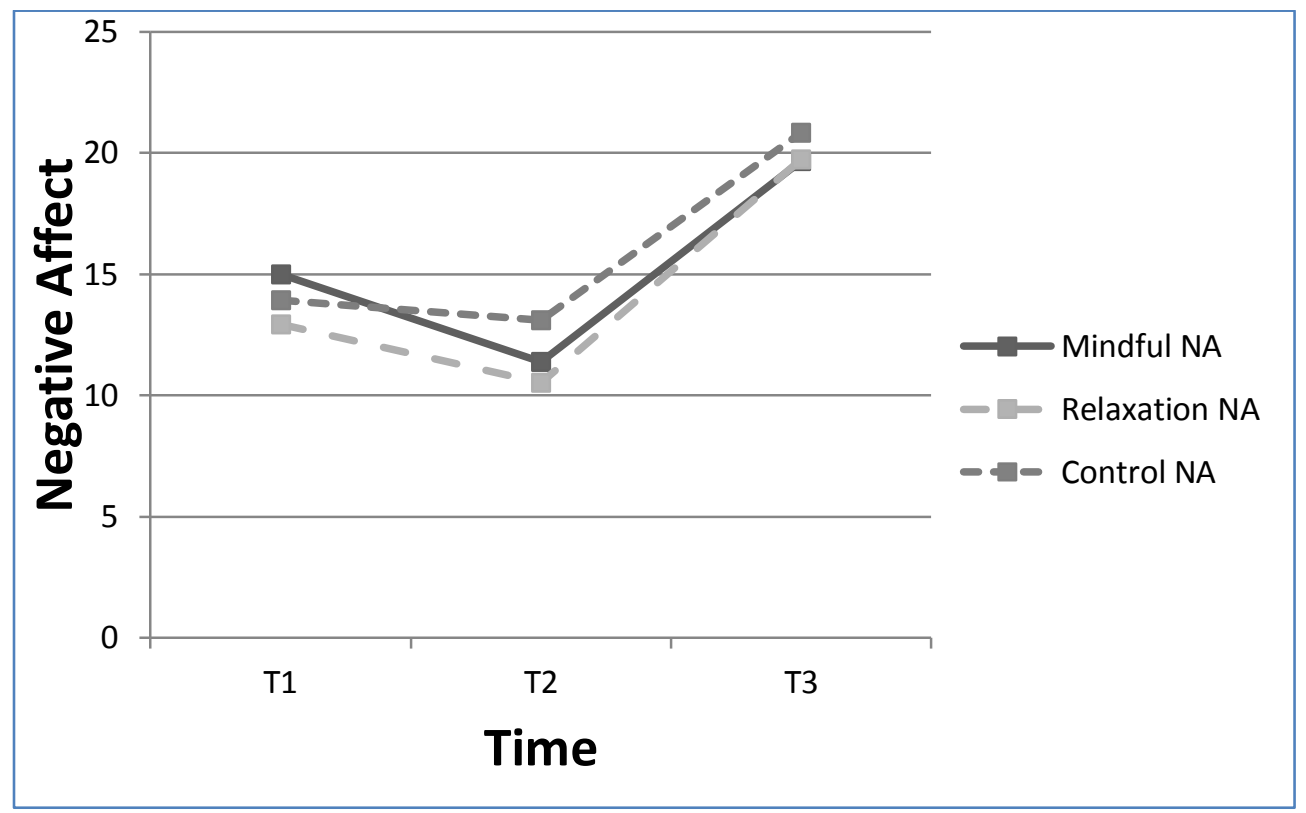

Figure 6. Level of NA over time by group.

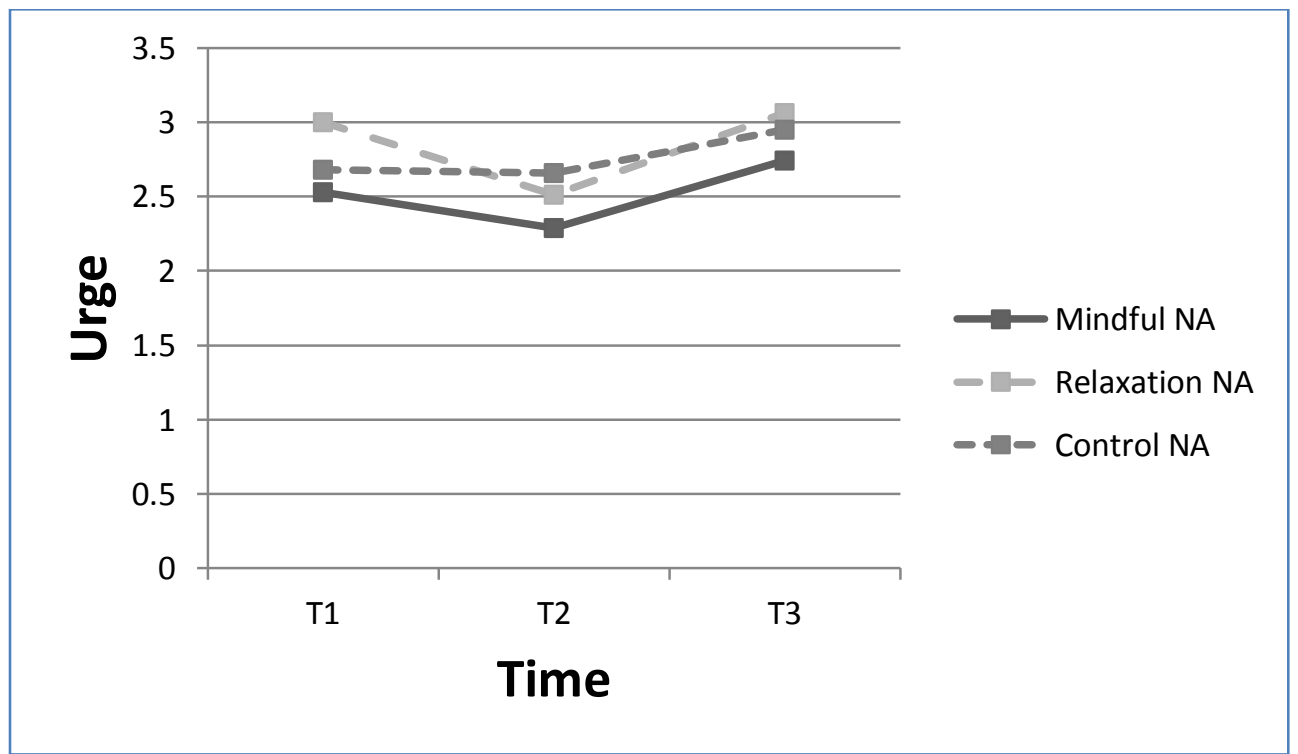

Figure 7. Level of urge to drink over time by group. 
Hypotheses 1b and 2b. One-way ANOVAs were conducted to examine whether those in the Mindfulness + NA Stimuli group were more willing to watch NA images and less likely to endorse drinking alcohol sooner than those in the Relaxation + NA Stimuli and Control + NA Stimuli groups. For Willingness to Watch Images, no significant differences between groups emerged $F(2,112)=.82, p=.44$. For Time to Next Drink, no significant differences emerged between groups $F(2,111)=.35, p=.71$ (see Table 7 for means and SDs). Thus, Hypotheses $1 \mathrm{~b}$ and $2 \mathrm{~b}$ were not supported. ${ }^{5}$

Table 7

Willingness to Watch Images and Time to Next Drink Means and Standard Deviations for Each Group at T3.

\begin{tabular}{|l|c|c|}
\hline & Images & Time to Next Drink (in hours) \\
\hline Mindfulness + NA & $2.21(1.53)$ & $61.29(92.35)$ \\
\hline Relaxation + NA & $2.46(2.12)$ & $49.96(44.40)$ \\
\hline Control + NA & $2.85(2.84)$ & $51.58(38.38)$ \\
\hline
\end{tabular}

Note. Standard deviations in parentheses.

\footnotetext{
${ }^{5}$ A multivariate analysis of variance (MANOVA) was also conducted (with all four DVs), as the four outcome variables are related and likely impact one another. However, the results of this MANOVA were also not significant, $F(8,212)=.45, p=.89$. It was decided that the repeated measure MANOVA (for NA and Urge) and one-way ANOVAs (for Images and Time to Next Drink) better represented the data, and thus were presented here.
} 


\section{DISCUSSION}

The present study was the first to examine the impact of a brief mindfulness intervention in a sample of problematic college student drinkers on NA as it related to urge to drink. This avenue of research holds significant potential, as substances are frequently used to manage NA, which can lead to problematic use (Baker et al., 2004). Mindfulness-based interventions may allow individuals who use alcohol to cope with NA to learn new strategies to manage NA through observing (not avoiding) unpleasant experiences with an attitude of nonjudgment (Kabat-Zinn, 1994). Limited research in this area has supported brief mindfulness interventions as a way to manage affect (Arch \& Craske, 2006; Ortner et al., 2007) and decrease cigarette use (Bowen \& Marlatt, 2009) in college students. Nonetheless, no study has examined the impact of a brief mindfulness-based intervention on both NA and urge to drink in a college student sample.

Results indicated that a 10-minute mindfulness intervention increased state levels of mindfulness from baseline, above and beyond that of the Relaxation and Control Groups. Further, baseline levels of NA decreased and that level of relaxation increased following the interventions, for both the Mindfulness and Relaxation groups (and not for the Control group). These changes are consistent with past findings that brief mindfulness interventions increase levels of mindfulness (e.g., Adams et al., 2013), decrease NA (e.g., Arch \& Craske, 2006), and increase levels of relaxation (e.g., Shapiro, 1982). The present study's findings extend prior research stating that mindfulness interventions are effective with certain populations, to now include problematic college student drinkers.

While the present study found that the brief mindfulness intervention was effective in increasing state levels of mindfulness and decreasing NA immediately following the intervention, these changes did not influence response to NA. Thus, participants undergoing the 
NA induction following the mindfulness intervention did not have decreases in NA, urge, or time to next drink, as well as not having an increase in willingness to watch NA images above and beyond that of the Relaxation and Control groups. In fact, all three groups increased on NA and urge from $\mathrm{T} 2$ to $\mathrm{T} 3$, indicating that none of the interventions differentially impacted the participants. Thus, despite the mindfulness intervention being effective at increasing state levels of mindfulness and decreasing NA from $\mathrm{T} 1$ to $\mathrm{T} 2$, the changes did not influence response to NA following the NA induction.

The study sample consisted of problematic college student drinkers. While brief mindfulness interventions have been effective at decreasing and managing NA for a sample of healthy undergraduates (Arch \& Craske, 2006), as well as decreasing number of cigarettes smoked at follow-up (Bowen \& Marlatt, 2009), perhaps such a brief intervention does not extend to problematic drinkers. Vernig and Orsillo (2009) compared alcohol dependent and nondependent college students on NA following brief mindfulness instructions. Results indicated that alcohol dependent participants who received the mindfulness instructions did not differ from the control group (also consisting of alcohol dependent participants) who viewed a nature video on levels of NA, following a NA induction. The present study attempted to address some of the limitations of the Vernig and Orsillo (2009) study by: (1) assessing drinking motives and only including those reporting a mood-control motive to participate, (2) utilizing a guided mindfulness meditation (instead of a video), (3) instructing participants to utilize mindfulness skills when watching NA images, and (4) assessing response to NA via asking how willing they would be to continue watching NA images. Despite these efforts, the current study also found that a brief mindfulness intervention did not result in lower NA (and subsequently urge to drink) than the relaxation intervention or control group. These findings, combined with that of Vernig 
\& Orsillo (2009), indicate that a brief mindfulness intervention is not effective at decreasing NA and urge in this sample.

A stronger mindfulness intervention may be necessary to impact NA and urge for a population of problematic drinkers. Prior research has indicated that lengthier interventions decrease various substance use behaviors (e.g., drinking, cigarette use), as well as NA (e.g., Bowen et al., 2006; Chen et al., 2010; Davis et al., 2007). Additionally, MBRP is an 8-week substance use treatment that incorporates several aspects of mindfulness into each session. Multiple studies have found MBRP to be effective at helping individuals better manage craving, decrease substance use craving, and decrease substance use behaviors (Bowen et al., 2009; Brewer et al., 2009; Witkiewitz et al., 2010).

Limitations of the present study include this being an undergraduate sample and therefore the results may be difficult to generalize to other populations. Additionally, many mindfulnessbased treatments involve extensive training in mindfulness meditation and it is likely that the brief, 10-minute intervention used here may have been too brief to assist participants in managing NA and urge. This sample did not consist of participants endorsing wanting to decrease or quit drinking (despite being deemed problematic drinkers via eligibility criteria). Consequently, any drinking urges may be more difficult to change, regardless of the intervention implemented. Additionally, drinking urges and not actual drinking behavior was assessed. Finally, no follow-up assessment of affect or urge was conducted. Bowen and Marlett (2009) upon examining smoking behaviors found that while urges to smoke and affect did not change immediately following a brief mindfulness intervention, actual smoking behaviors decreased at the 7-day follow-up when compared to the control group. The authors suggested that over the 
week, participant response to smoking behaviors may have changed and thus they decreased their cigarette use.

The current study also had several strengths, particularly regarding study design. Control groups were included in order to assess effectiveness of each intervention and the mood manipulation, and to confirm that any changes found were in fact due to the active intervention or mood induction and not to random factors. Manipulation checks revealed that the mindfulness and relaxation interventions were effective at increasing mindfulness and relaxation, respectively, beyond changes seen in the Control group. Further, the mindfulness intervention increased state levels of mindfulness above that of the Control group and on the Curiosity subscale for the Relaxation group. This finding indicates that the mindfulness manipulation was truly effective at increasing level of mindfulness, and was not just helping participants physically relax. Additionally, the NA induction was effective at increasing levels of NA, while the neutral induction was not. To our knowledge, this is the first study to observe increases in state mindfulness (according to the TMS) in a sample of problematic, college student drinkers following a brief mindfulness intervention. Thus, future research should consider utilizing similar interventions to alter levels of mindfulness, relaxation, and NA.

This study also had a large sample size and was adequately powered for the primary analyses (observed power $=.87$ ). The sample consisted of problematic drinkers with an average AUDIT score of $10.03(S D=4.28)$, considered to be indicative of hazardous drinking (Fleming et al., 1991; Kokotailo et al., 2004). Further, drinking motives were assessed and only those with elevations on Enhancement and Coping (both motives targeting affect) were included. Thus, the targeted sample population was appropriate for the goals of the study. 
Future research should consider stronger mindfulness interventions when targeting problematic drinkers. Such an intervention may consist of multiple sessions, homework, and/or guidance from a trained clinician in utilizing mindfulness. Second, follow-up assessments with participants would be useful, given prior research indicating no initial changes in affect or urge, but changes in substance behavior at follow-up (Bowen \& Marlatt, 2009). And third, a treatmentseeking population may yield better results on NA and urge, given that their goal may be to reduce drinking behaviors and better manage mood. Knowing that NA is often viewed as a trigger for use, and has implications for relapse, any intervention that assists an individual to better manage NA would be beneficial. Given the initial effectiveness of the mindfulness and relaxation interventions in the present study, modeling future interventions from these may be useful. 


\section{REFERENCES}

Adams, C. E., Benitez, L., Kinsaul, J., McVay, M., Barbry, A., Thibodeaux, A., \& Copeland, A. L. (2013). Effects of brief mindfulness instructions on reactions to body image stimuli among female smokers: An experimental study. Nicotine \& Tobacco Research, 15(2), 376-384. doi:10.1093/ntr/nts133

Antoni, M. H. (2003). Stress management intervention for women with breast cancer. Washington, D.C.: American Psychological Association.

Arch, J. J., \& Craske, M. G. (2006). Mechanisms of mindfulness: Emotion regulation following a focused breathing induction. Behaviour Research and Therapy, 44(12), 1849-1858. doi:10.1016/j.brat.2005.12.007

Armeli, S., Tennen, H., Todd, M., Carney, M., Mohr, C., Affleck, G., \& Hromi, A. (2003). A daily process examination of the stress-response dampening effects of alcohol consumption. Psychology of Addictive Behaviors, 17(4), 266-276. doi:10.1037/0893164X.17.4.266

Babor, T. F., Higging-Biddle, J. C., Saunders, J. B., \& Monteiro, M. G. (2001). AUDIT: The Alcohol Use Disorders Identification Test: Guidelines for use in primary care. Guidelines for use in primary care: World Health Organization.

Baer, R. (2003). Mindfulness training as a clinical intervention: A conceptual and empirical review. Clinical Psychology: Science and Practice, 10, 125-143. doi: 10.1093/clipsy.bpg015

Baer, R. A., Smith, G. T., Hopkins, J., Krietemeyer, J., \& Toney, L. (2006). Using self-report assessment methods to explore facets of mindfulness. Assessment, 13, 27-45. doi: $10.1177 / 1073191105283504$

Baker, T. B., Piper, M. E., McCarthy, D. E., Majeskie, M. R., \& Fiore, M. C. (2004). Addiction motivation reformulated: An affective processing model of negative reinforcement. Psychological Review, 111, 33-51. doi: 10.1037/0033-295X.111.1.33

Bernstein, D. A., \& Borkovec, T. D. (1973). Progressive relaxation training: A manual for the helping professions. Champaign, IL: Research Press.

Black, D. S., Semple, R. J., Pokhrel, P., \& Grenard, J. L. (2011). Component processes of executive function - mindfulness, self-control, and working memory - and their relationships with mental and behavioral health. Mindfulness, 2, 179-185. doi: $10.1007 / \mathrm{s} 12671-011-0057-2$ 
Bowen, S., Chawla, N., Collins, S., Witkiewitz, K., Hsu, S.,Grow, J., ... Marlatt, G.A. (2009). Mindfulness-based relapse prevention for substance use disorders: A pilot efficacy trial. Substance Abuse, 30, 295-305. doi: 10.1080/08897070903250084

Bowen, S., Chawla, N., \& Marlatt, G. A., (2011). Mindfulness-based relapse prevention for addictive behaviors: A clinician's guide. New York, NY: Guilford Press.

Bowen, S., \& Marlatt, A. (2009). Surfing the urge: Brief mindfulness-based intervention for college student smokers. Psychology of Addictive Behaviors, 23, 666-671. doi: $10.1037 / \mathrm{a} 0017127$

Bowen, S., Wikiewitz, K., Dillworth, T. M., Chawla, N., Simpson, T. L., Ostafin, B. D....Marlatt, G. A. (2006). Mindfulness meditation and substance use in an incarcerated population. Psychology of Addictive Behaviors, 20, 343-347. doi: 10.1037//0893

Breslin, F. C., Zack, M., \& McMain, S. (2002). An information-processing analysis of mindfulness: Implications for relapse prevention in the treatment of substance abuse. Clinical Psychology: Science and Practice, 9, 275-299.

Brewer, J. A., Sinha, R., Chen, J. A., Michalsen, R. N., Babuscio, T. A., Nich, C., ...Rounsaville, B. J. (2009). Mindfulness training and stress reactivity in substance abuse: Results from a randomized, controlled stage I pilot study. Substance Abuse, 30, 306-317. doi: $10.1080 / 08897070903250241$

Brown, K., \& Ryan, R. M. (2003). The benefits of being present: Mindfulness and its role in psychological well-being. Journal of Personality and Social Psychology, 84(4), 822-848. doi:10.1037/0022-3514.84.4.822

Chen, K. W., Comerford, A., Shinnick, P., \& Ziedonis, D. M. (2010). Introducing Qigong meditation into residential addiction treatment: A pilot study where gender makes a difference. The Journal of Alternative and Complimentary Medicine, 16, 875-882. doi: 10.1089/acm.2009.0443

Conklin, C. A., \& Perkins, K. A. (2005). Subjective and reinforcing effects of smoking during negative mood induction. Journal of Abnormal Psychology, 114, 153-164.

Cooney, N. L., Litt, M. D., Morse, P. A., Bauer, L. O., \& Gaupp, L. (1997). Alcohol cue reactivity, negative-mood reactivity, and relapse in treated alcoholic men. Journal of Abnormal Psychology, 106(2), 243-250. doi: 10.1037/0021-843X.106.2.243

Cooper, M. L. (1994). Motivations for alcohol use among adolescents: Development and validation of a four-factor model. Psychological Assessment, 6, 117-128. doi: 1040$3590 / 94$ 
Davidson, R. J., Kabat-Zinn, J., Schumacher, J., Rosenkranz, M., Muller, D., Santorelli, S. F., ... Sheridan, J. F. (2003). Alterations in brain and immune function produced by mindfulness meditation. Psychosomatic Medicine, 65(4), 564-570. doi:10.1097/01.PSY.0000077505.67574.E3

Davis, J. M., Fleming, M. F., Bonus, K. A., \& Baker, T. B. (2007). A pilot study on mindfulness based stress reduction for smokers. BMC Complementary and Alternative Medicine, 7, 17. doi: $10.1186 / 1472-6882-7-2$

Faul, F., Erdfelder, E., Lang, A. G., \& Buchner, A. (2007). G*Power 3: A flexible statistical power analysis program for the social, behavioral, and biomedical sciences. Behavior Research Methods, 39, 175-191.

Fernandez, A. C., Wood, M. D., Stein, A. R., \& Rossi, J. S. (2010). Measuring mindfulness and examining its relationship with alcohol use and negative consequences. Psychology of Addictive Behaviors, 24, 608-616. doi: 10.1037/a0021742

Fleming, M. F., Barry, K. L., \& MacDonald, R. (1991). The Alcohol Use Disorders Identification Test (AUDIT) in a college sample. International Journal of the Addictions, 26(11), 1173-1185.

Grossman, P., Niemann, L., Schmidt, S., \& Walach, H. (2004). Mindfulness-based stress reduction and health benefits: A meta-analysis. Journal of Psychosomatic Research, 57, 35-43. doi: 10.1111/j.2042-7166.2003.tb04008.x

Hayes, S. C., Strosahl, K., \& Wilson, K. G. (1999). Acceptance and commitment therapy: An experiential approach to behavior change. New York, NY: Guilford.

Jain, S., Shapiro, S. L., Swanick, S., Roesch, S. C., Mills, P. J., Bell, I., \& Schwartz, G. R. (2007). A randomized controlled trial of mindfulness meditation versus relaxation training: Effects on distress, positive states of mind, rumination, and distraction. Annals of Behavioral Medicine, 33(1), 11-21. doi:10.1207/s15324796abm3301_2

Jennison, K. M. (2004). The short-term effects and unintended long-term consequences of binge drinking in college: A 10-year follow-up study. The American Journal of Drug and Alcohol Abuse, 30, 659-684. doi: 10.1081/ADA-200032331

Kabat-Zinn, J. (1982). An outpatient program in behavioral medicine for chronic pain patients based on the practice of mindfulness meditation: Theoretical considerations and preliminary results. General Hospital Psychiatry, 4, 33-47.

Kabat-Zinn, J. (1990). Full catastrophe living: Using the wisdom of your body and mind to face stress, pain, and illness. New York, NY: Delacourt. 
Kabat-Zinn, J. (1994). Wherever you go, there you are: Mindfulness meditation in everyday life. New York, NY: Hyperion.

Kabat-Zinn, J. (2002). Sitting meditations. On Guided mindfulness meditation [compact disc]. Lexington, MA: Stress Reduction CDs and Tapes.

Kabat-Zinn, J., Lipworth, L., \& Burney, R. (1985). The clinical use of mindfulness meditation for the self-regulation of chronic pain. Journal of Behavioral Medicine, 8, 163-190.

Kodl, M. M., Fu, S. S., Willenbring, M. L., Gravely, A., Nelson, D. B., \& Joseph, A. (2008). The impact of depressive symptoms on alcohol and cigarette consumption following treatment for alcohol and nicotine dependence. Alcoholism: Clinical and Experimental Research, 32(1), 92-99. doi:10.1111/j.1530-0277.2007.00556.x

Kokotailo, P. K., Egan, J., Gangnon, R., Brown, D., Mundt, M., \& Fleming, M. (2004). Validity of the Alcohol Use Disorders Identification Test in college students. Alcoholism: Clinical and Experimental Research, 28(6), 914-920. doi: 10.1097/01.ALC.0000128239.87611.F5

Kozlowski, L. T., \& Wilkinson, D. A. (1987). Use and misuse of the concept of craving by alcohol, tobacco, and drug researchers. British Journal of Addiction, 82, 31-36.

Kushner, M. G., Mackenzie, T. B., Fiszdon, J., Valentiner, D. P., \& Foa, E. (1996). The effects of alcohol consumption on laboratory-induced panic and state anxiety. Archives of General Psychiatry, 53(3), 264-270.

Lang, P. J., Bradley, M. M., \& Cuthbert, B. N. (2005). International affective picture system (IAPS): Affective ratings of pictures and instruction manual. Technical Report A-6. University of Florida, Gainesville, FL.

Lau, M. A., Bishop, S. R., Segal, Z. V., Buis, T., Anderson, N. D., Carlson, L., \& ... Devins, G. (2006). The Toronto mindfulness scale: Development and validation. Journal of Clinical Psychology, 62(12), 1445-1467. doi:10.1002/jclp.20326

Linehan, M. (1993). Cognitive-behavioral treatment of borderline personality disorder. New York: Guilford.

Linehan, M. M., Armstrong, H. E., Suarez, A., \& Allmon, D. (1991). Cognitive-behavioral treatment of chronically parasuicidal borderline patients. Archives of General Psychiatry, 48(12), 1060-1064.

MacLean, M. G., \& Lecci, L. (2000). A comparison of models of drinking motives in a university sample. Psychology of Addictive Behaviors, 14(1), 83-87. doi:10.1037/0893164X.14.1.83 
Marlatt, G.A. (2002). Buddhist philosophy and addictive behavior. Cognitive and Behavioral Practice, 9, 44-50. doi: 1077-7229/02/44

McKee, L., Zvolensky, M. J., Solomon, S. E., Bernstein, A., \& Leen-Feldner, E. (2007). Emotional-vulnerability and mindfulness: A preliminary test of associations among negative affectivity, anxiety sensitivity, and mindfulness skills. Cognitive Behaviour Therapy, 36(2), 91-100. doi:10.1080/16506070601119314

Monti, P. M., Rohsenow, D. J., \& Hutchison, K. E. (2000). Toward bridging the gap between biological, psychobiological, and psychosocial models of alcohol craving. Addiction, 95, 229-236.

Ortner, C. M., Kilner, S. J., \& Zelazo, P. (2007). Mindfulness meditation and reduced emotional interference on a cognitive task. Motivation and Emotion, 31(4), 271-283. doi:10.1007/s11031-007-9076-7

Ostafin, B. D., \& Marlatt, G. A. (2008). Surfing the urge: Experiential acceptance moderates the relation between automatic alcohol motivation and hazardous drinking. Journal of Social and Clinical Psychology, 27(4), 404-418.

Parrott, A. C., \& Garnham, N. J. (1998). Comparative mood states and cognitive skills of cigarette smokers, deprived smokers, and nonsmokers. Human Psychopharmacology, 13, 367-376.

Perkins, H. W. (2002). Surveying the damage: A review of research on consequences of alcohol misuse in college populations. Journal on Studies of Alcohol, 14, 91-139.

Philip, A. C. (2010). More than meditation: The role of dispositional mindfulness in alcohol and marijuana-related problems (unpublished thesis). Auburn University, Auburn, Alabama.

Raes, F., Dewulf, D., Van Heeringen, C., \& Williams, J. G. (2009). Mindfulness and reduced cognitive reactivity to sad mood: Evidence from a correlational study and a nonrandomized waiting list controlled study. Behaviour Research and Therapy, 47(7), 623627. doi:10.1016/j.brat.2009.03.007

Saunders, J. B., Aasland, O. G., Babor, T. F., de la Fuente, J. R., \& Grant, M. (1993). Development of the Alcohol Use Disorders Identification Test (AUDIT): WHO collaborative project on early detection of persons with harmful alcohol consumption II. Addiction, 88, 791-804.

Segal, Z. V., Williams, J. M. G., \& Teasdale, J. D. (2002). Mindfulness-based cognitive therapy for depression: A new approach to preventing relapse. New York, NY: Guilford.

Shapiro, D. H. (1982). Overview: Clinical and physiological comparison of meditation with other self-control strategies. The American Journal of Psychiatry, 139(3), 267-274. 
Shapiro, S. L., Bootzin, R. R., Figueredo, A. J., Lopez, A., \& Schwartz, G. E. (2003). The efficacy of mindfulness-based stress reduction in the treatment of sleep disturbance in women with breast cancer: An exploratory study. Journal of Psychosomatic Research, 54(1), 85-91. doi:10.1016/S0022-3999(02)00546-9

Shapiro, S. L., Carlson, L. E., Astin, A. J., \& Freedman, B. (2006). Mechanisms of mindfulness. Journal of Clinical Psychology, 62, 373-386.

Shiffman, S., Balabanis, M. H., Gwaltney, C. J., Paty, J. A., Gnys, M., Kassel, J. D., \& ... Paton, S. M. (2007). Prediction of lapse from associations between smoking and situational antecedents assessed by ecological momentary assessment. Drug and Alcohol Dependence, 91(2-3), 159-168. doi:10.1016/j.drugalcdep.2007.05.017

Singh, N. N., Lancioni, G. E., Winton, A. S. W., Adkins, A. D., Wahler, R. G., Sabaawi, M., \& Singh, J. (2007). Individuals with mental illness can control their aggressive behavior through mindfulness training. Behavior Modification, 31, 313-328.

Soler, J., Valdepérez, A., Feliu-Soler, A., Pascual, J. C., Portella, M. J., Martín-Blanco, A., \& ... Pérez, V. (2011). Effects of the dialectical behavioral therapy-mindfulness module on attention in patients with borderline personality disorder. Behaviour Research and Therapy, 150, 150-157. doi:10.1016/j.brat.2011.12.002

Speca, M., Carlson, L. E., Goodey, E., \& Angen, M. (2000). A randomized, wait-list controlled clinical trial: The effect of a mindfulness meditation-based stress reduction program on mood and symptoms of stress in cancer outpatients. Psychosomatic Medicine, 62(5), 613622.

Substance Abuse and Mental Health Services Administration, Results from the 2010 National Survey on Drug Use and Health: Summary of National Findings, (2011). NSDUH Series H-41, HHS Publication No. (SMA) 11-4658. Rockville, MD: Substance Abuse and Mental Health Services Administration.

Tang, Y., Ma, Y., Fan, Y., Feng, H., Wang, J., Feng, S., \& ...Fan, M. (2009). Central and autonomic nervous system interaction is altered by short-term meditation. Proceedings of the National Academy of Sciences, 106, 8865-8870. doi: 10.1073.pnas.0904031106.

Tang, Y., Ma, Y., Wang, J., Fan, Y., Feng, S., Lu, Q., \& ...Posner, M. (2007). Short-term meditation training improves attention and self-regulation. Proceedings of the National Academy of Sciences, 104, 17152-17156. doi: 10.1073/pnas.0707678104.

Teasdale, J. D., Segal, Z. V., Williams, J. G., Ridgeway, V. A., Soulsby, J. M., \& Lau, M. A. (2000). Prevention of relapse/recurrence in major depression by mindfulness-based cognitive therapy. Journal of Consulting and Clinical Psychology, 68(4), 615-623. doi:10.1037/0022-006X.68.4.615 
Thompson, B. L., \& Waltz, J. (2007). Everyday mindfulness and mindfulness meditation: Overlapping constructs or not? Personality and Individual Differences, 43, 1875-1885. doi: $10.1016 /$ j.paid.2007.06.017

Vernig, P. M., \& Orsillo, S. M. (2009). Psychophysiological and self-reported emotional responding in alcohol-dependent college students: The impact of brief acceptance/mindfulness instruction. Cognitive Behaviour Therapy, 38, 174-183. doi: 10.1080/16506070902767563.

Vik, P. W., Carrello, P., Tate, S. R., \& Field, C. (2000). Progression of consequences among heavy-drinking college students. Psychology of Addictive Behaviors, 14, 91-101. doi: $10.1037 / / 0893$

Vinci, C., Copeland, A. L., \& Carrigan, M. H. (2012). Exposure to negative affect cues and urge to smoke. Experimental and Clinical Psychopharmacology, 20, 47-55. doi: $10.1037 / \mathrm{a} 0025267$

Watson, D., Clark, L. A., \& Tellegen, A. (1988). Development and validation of brief measures of positive and negative affect: The PANAS scales. Journal of Personality and Social Psychology, 54, 1063-1070.

Wechsler, H., Lee, J. E., Kuo, M., Seibring, M., Nelson, T. F., \& Lee, H. (2002). Trends in college binge drinking during a period of increased prevention efforts. Journal of American College Health, 50(5), 203-217.

West, R. (2006). Theory of Addiction. Oxford, UK: Blackwell Publishing.

Willner, P., \& Jones, C. (1996). Effects of mood manipulation on subjective and behavioural measures of cigarette craving. Behavioural Pharmacology, 7, 355-363.

Witkiewitz, K., \& Bowen, S. (2010). Depression, craving and substance use following a randomized trial of mindfulness-based relapse prevention. Journal of Consulting and Clinical Psychology, 78, 362-374. doi: 10.1037/a0019172

Witkiewitz, K., Marlatt, G. A., \& Walker, D. (2005). Mindfulness-based relapse prevention for alcohol and substance use disorders. Journal of Cognitive Psychotherapy: An International Quarterly, 19, 211-228.

Witkiewitz, K., \& Villarroel, N. (2009). Dynamic association between negative affect and alcohol lapses following alcohol treatment. Journal of Consulting and Clinical Psychology, 77(4), 633-644. doi:10.1037/a001567 


\section{APPENDIX A MINDFULNESS INSTRUCTIONS}

"While sitting down in your chair, place your feet flat on the floor. Sit up straight. Relax your shoulders, relax your neck, and place your hands in your lap or on your knees. As you settle into a comfortable position, commit yourself to simply being fully awake, fully present for these next few moments. If you feel comfortable with it, gently close your eyes. Otherwise, just look toward the floor.

Focus on tuning into the feeling of the breath moving in and out of your body. Focus on the sensation of the breath moving through your nose on each inbreath and each outbreath. Allow yourself to just be here in this moment, following the breath as it comes in and as it goes out. Just breathe and let go. Breathe and let be.

Naturally your mind may wander off into thoughts of one kind or another. Take note of any thoughts as they come up. Note what's on your mind and how your body is feeling. Acknowledge these thoughts, whatever they are, without judging or evaluating them. And then just gently let them go. Bring your attention back to the breath, focusing on the feeling of the breath coming in and out of your nostrils.

And each time you notice that your mind has gone off somewhere else, wherever that may be, just bring your attention back to the feeling of the breath. And if the mind wanders off a thousand times, you simply bring it back a thousand times, intentionally cultivating an attitude of patience and gentleness towards yourself. This means choosing as best you can not to react to or judge any of your thoughts or feelings, impulses or perceptions, reminding yourself instead that absolutely anything that comes into the field of awareness is ok. We simply sit with it and breathe with it and observe it, staying open and awake in the present moment, right here, right now, a continual process of seeing and letting be, seeing and letting go, rejecting nothing, pursuing nothing, dwelling in stillness and in calmness as the breath moves in and out.

If you'd like, commit yourself to bringing this attitude of attention and acceptance with you throughout your day, being fully aware in the present moment, noticing any thoughts or feelings that may arise, without judging them - just being right here and right now, accepting the present moment, and accepting yourself, no matter what happens. Remember that you can always bring your focus back to your breath, back to the sensations of the present moment, to cultivate this sense of attention and acceptance." 


\section{APPENDIX B \\ PHYSICAL RELAXATION INSTRUCTIONS}

"While sitting down in your chair, place your feet flat on the floor. Sit up straight. Relax your shoulders, relax your neck, and place your hands in your lap or on your knees. If you feel comfortable with it, gently close your eyes. Otherwise, just look toward the floor.

For the next several minutes, I would like you to try and relax your body. Start by taking a few deep breaths to relax. As you do so, your body may physically begin to feel more relaxed. Continue to take a few more deep breaths, and let go of any tension you may feel. Just allow yourself to relax.

Draw your attention to the muscles in your right hand and relax them. Release any tension in your hand. You may begin to feel more heavy. Now, relax your left hand. Just let the muscles go. Relax your entire right arm in a similar way. Allow your muscles to feel more and more relaxed. Shift your attention to your left arm and relax it as well. Continue to release any tension in your hands and arms feel.

Relax the muscles in your face and neck. Slowly notice how your body is feeling more and more heavy with relaxation. Continue to allow all the muscles in your face and neck to relax. Your upper body may feel more relaxed now than it did when you first started to relax your muscles.

Draw you attention to your chest and shoulders. Allow your chest and shoulders to relax. Recognize how your body may feel warm and heavy as you continue to relax more deeply. Just let the muscles go. Relax the muscles in on your abdomen and back. Again, just allow all of these muscles to relax. Continue to relax. You may feel less tense and more relaxed.

Attend to the muscles in your upper leg and tell these muscles to relax as well. Notice the relaxation you are experiencing. Continue to relax by relaxing your calves. Your body may be becoming more heavy and relaxed. Let your body relax and release any tension. You may feel more relaxed not than you did initially. Shift your attention to your feet. Again, allow all the muscles around your feet to relax.

While continuing to relax your body, take a few more deep breaths. Your hands, arms, face, and neck may feel more relaxed. Also your chest, shoulders, abdomen and back may be less tense. Finally, the muscles in your legs and feet may also be more relaxed. Take one more deep breath in and out and slowly open your eyes." 


\section{APPENDIX C \\ AFFECT INSTRUCTIONS}

"You will sit and watch pictures appear on the screen in front of you while listening to music. I want you to concentrate on the pictures and the music and vividly imagine that you are actually witnessing or even participating in the scene or activity you are viewing. When I say imagine vividly, I mean that I would like you to focus so intensely on the picture that not only can you feel emotionally what it would feel like to witness that scene right now, but you can feel physically, how your body would feel, if you were immediately confronted with each scene. Just allow yourself to feel that way."

Those in the mindfulness group will also be read these additional instructions: "A few minutes ago you listened to a tape instructing you to focus on your breath, while redirecting your thoughts to the present moment. The tape also asked you to not to react to or judge any of your thoughts or feelings, impulses or perceptions, reminding yourself instead that absolutely anything that comes into the field of awareness is ok. When watching these images, try to utilize those instructions, being fully aware in the present moment, noticing any thoughts or feelings that may arise, without judging them - just being right here and right now, accepting the present moment, and accepting yourself, no matter what happens."

Those in the relaxation group will be read these additional instructions: "A few minutes ago you listened to a tape instructing you to physically relax your body. When watching these images, consider utilizing those instructions to continue to physically relax your muscles." 


\section{APPENDIX D COPYRIGHT INFORMATION}

Link for information regarding author publishing rights for dissertations regarding the journal, Behaviour Research and Therapy: http://www.elsevier.com/journal-authors/author-rights-andresponsibilities 


\section{APPENDIX E}

\section{IRB APPROVAL FORM}

\section{ACTION ON PROTOCOL APPROVAL REQUEST}

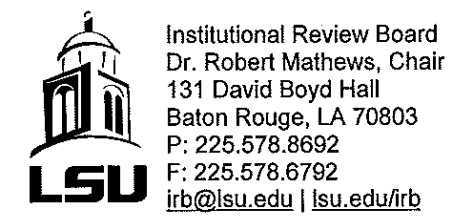
TO: $\quad$ Amy Copeland Psychology
FROM: $\quad$ Robert C. Mathews Chair, Institutional Review Board
DATE: June 4, 2012
RE: $\quad$ IRB\# 3285
TITLE: $\quad$ Alcohol Use and Mood

New Protocol/Modification/Continuation: New Protocol

Review type: Full __ Expedited $X$ Review date: 6/5/2012

Risk Factor: Minimal _ $\mathrm{X}$ Uncertain __ Greater Than Minimal

Approved_ $X \quad$ Disapproved

Approval Date: $\underline{6 / 5 / 2012}$ Approval Expiration Date: $\underline{6 / 4 / 2013}$

Re-review frequency: (annual unless otherwise stated)

Number of subjects approved: $\underline{200}$

Protocol Matches Scope of Work in Grant proposal: (if applicable)

By: Robert C. Mathews, Chairman Dolpt

PRINCIPAL INVESTIGATOR: PLEASE READ THE FOLLOWING Continuing approval is CONDITIONAL on:

1. Adherence to the approved protocol, familiarity with, and adherence to the ethical standards of the Belmont Report, and LSU's Assurance of Compliance with DHHS regulations for the protection of human subjects*

2. Prior approval of a change in protocol, including revision of the consent documents or an increase in the number of subjects over that approved.

3. Obtaining renewed approval (or submittal of a termination report), prior to the approval expiration date, upon request by the IRB office (irrespective of when the project actually begins); notification of project termination.

4. Retention of documentation of informed consent and study records for at least 3 years after the study ends.

5. Continuing attention to the physical and psychological well-being and informed consent of the individual participants, including notification of new information that might affect consent.

6. A prompt report to the IRB of any adverse event affecting a participant potentially arising from the study.

7. Notification of the IRB of a serious compliance failure.

8. SPECIAL NOTE:

*All investigators and support staff have access to copies of the Belmont Report, LSU's Assurance with DHHS, DHHS (45 CFR 46) and FDA regulations governing use of human subjects, and other relevant documents in print in this office or on our World Wide Web site at http://www.lsu.edu/irb 
Application for:

Approval of Projects Which Use Human Subjects

This application is used for projects/study's that cannot be

reviewed through the exemption process.

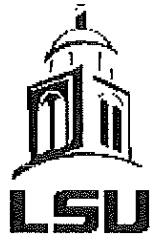

Institutional Review Board Dr. Robert Mathews, Chair 203 B-1 David Boyd Hall Baton Rouge, LA 70803

P: 225.578 .8692

F: 225.578.6792

irb@lsu.edu ] Isu.edu/irb

$>$ Applicant, Please fill out the application in its entirety and include two copies of the completed application as well as parts A-E, listed below. Once the application is completed, please submit it to the IRB Office for review and please allow ample time for the application to be reviewed. Expedited review usually takes 1-2 weeks. Full reviews are held at the bimonthly IRB meetings 2 nd week of Feb. Apr, June, Aug, Oct, Dec. Carefully completed applications should be submitted 2 weeks before a meeting to ensure a prompt decision.

$>$ A Complete Application Includes All of the Following:

(A) Two copies of this completed form and two copies of parts B thru E.

(B) A complete copy of any grant proposal relevant to the project.

(C) Copies of all instruments to be used.

- If this proposal is a part of a grant application, include a copy of the grant proposal, the investigative brochure (if one exists) and any recruitment materials including advertisements intended to be seen or heard by potential subjects.

(D) The consent form that will be used. A copy of the Waiver of Signed Informed Consent is attached and must be completed only if there is the intention to use an unsigned consent form. The script to be used as the unsigned consent script MUST be included with the waiver of signed informed consent.

(E) Certificate of Completion of Human Subjects Protection Training for all personnel involved in the project, including students who are involved with testing or handling data, unless already on file with the IRB. Training link http:/l cme.cancer.gov/clinicaltrials/learning/humanparticipant-protections.asp.

1) Principal Investigator: Amy Copeland

Rank:Associate

*PI must be an LSU Faculty member

Dept:: Psychology

Ph: 225.578.4117 E-Mail: copelan@ilsu.edu

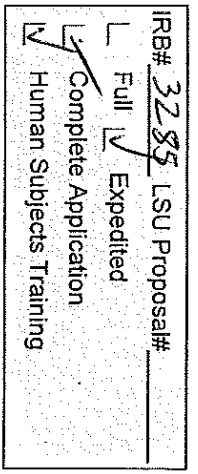

2) Co Investigator $1 * *$ : Christine Vinci

Rank: arad student

**Student? $\mathrm{Y} / \mathrm{N} Y$ Thesis/dissertation/class project? $\mathrm{Y} / \mathrm{N} \underline{\mathrm{Y}}$

Dept.: Psychology Ph:225.578.1494 E-Mail: cvinci28@gmail.com

3) All other Co Investigators: please include department, rank, and e-mail for each

4) Project Title: Alcohol Use and Mood

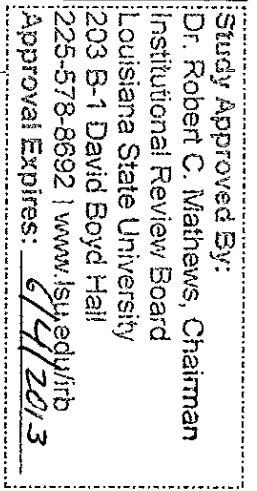

5) Proposed Start Date: $06 / 01 / 12$

6) Proposed Duration Months: 12

7) Number of Subjects Requested: 200 8) LSU Proposal\#

9) Funding Sought From: N/A

***Incomplete applications will not be processed. Effective August 1, 2007, incomplete applications will only be kept on file for two years. ${ }^{* * *}$ 


\section{VITA}

Christine Vinci is originally from Kenner, LA. She completed her B.S. in psychology from Louisiana State University (LSU) and received her M.S. in applied clinical psychology from the University of South Carolina Aiken. Following this, she entered the clinical psychology doctoral program at LSU. She completed her clinical internship at the University of Mississippi Medical Center/G.V. (Sonny) Montgomery Veteran Affairs Medical Center. She will soon begin her postdoctoral research fellowship at the MD Anderson Cancer Center in Houston, Texas. 